
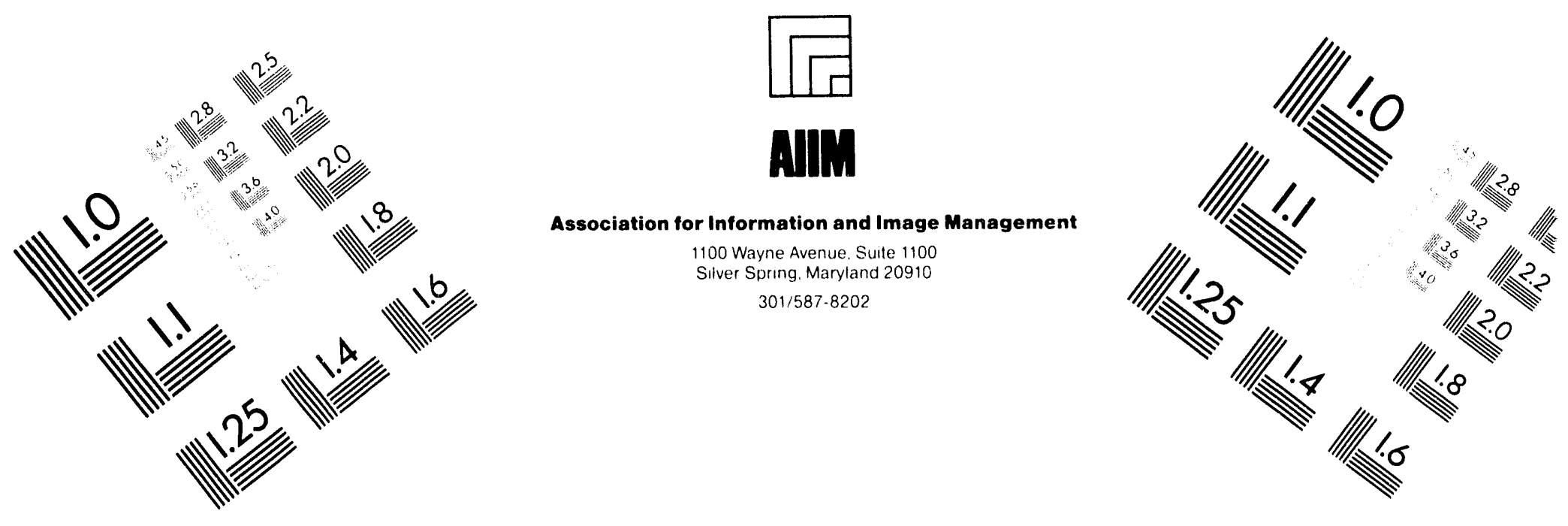

\title{
Centimeter
}

2
2 Inches
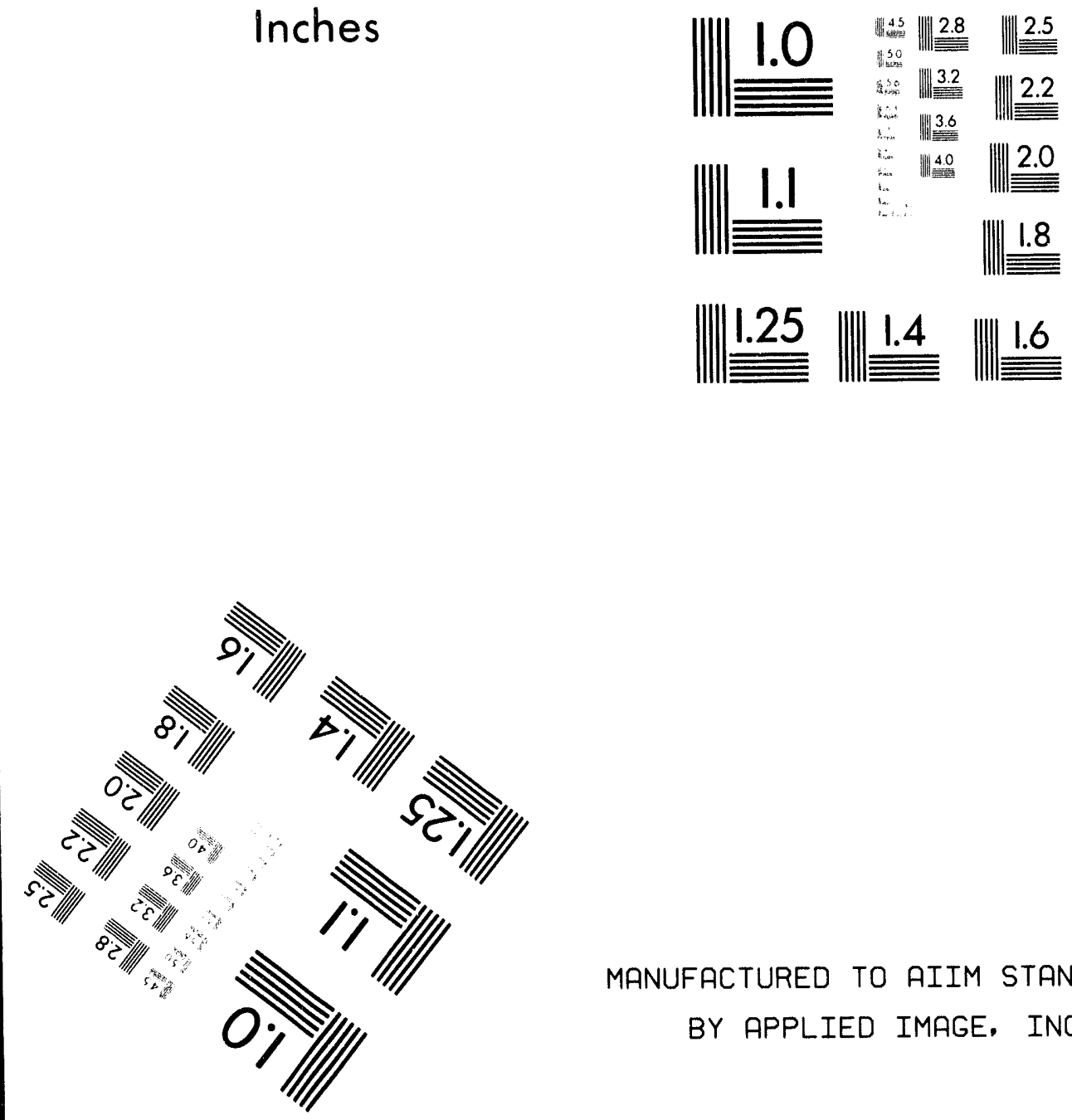

MANUFACTURED TO AIIM STANDARDS

BY APPLIED IMAGE, INC.

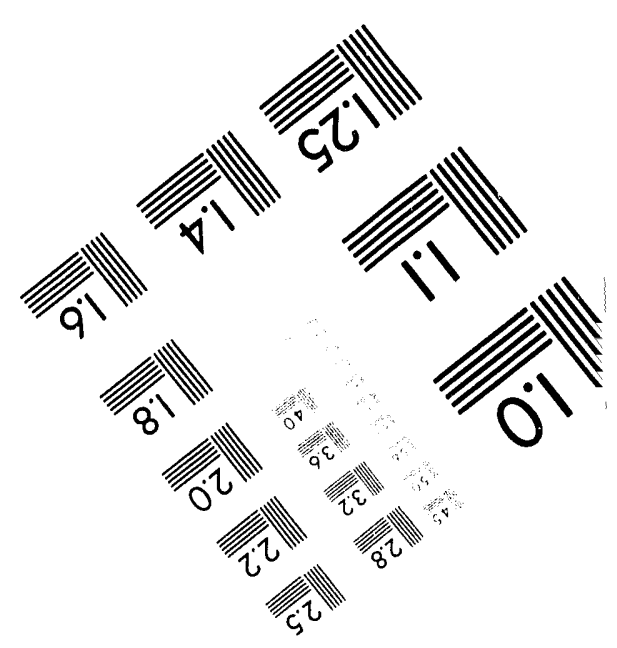



DOE/AL62353-1

\section{SPARK IGNITED TURBULENT FLAME KERNEL GROWTH}

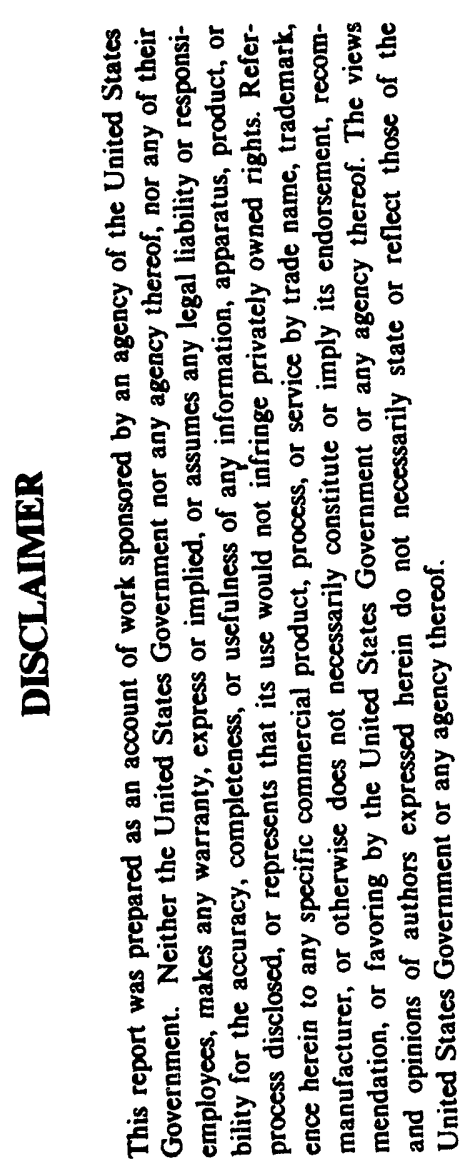

Annual Report for the Period January-December 1991

Domenic A. Santavicca

PENN STATE UNIVERSITY

University Park, PA 16802

Date Published - June 1994

PREPARED FOR THE UNITED STATES DEPARTMENT OF ENERGY

Under Contract No. DE-FG04-90AL62353 


\section{ABSTRACT}

An experimental study of the effect of spark power on the growth rate of spark-ignited flame kernels was conducted in a turbulent flow system at $1 \mathrm{~atm}, 300 \mathrm{~K}$ conditions. All measurements were made with premixed, propane-air at a fuel/air equivalence ratio of 0.93 , with $0 \%, 8 \%$ or $14 \%$ dilution. Two flow conditions were studied: a low turbulence intensity case with a mean velocity of $1.25 \mathrm{~m} / \mathrm{sec}$ and a turbulence intensity of $0.33 \mathrm{~m} / \mathrm{sec}$, and a high turbulence intensity case with a mean velocity of $1.04 \mathrm{~m} / \mathrm{sec}$ and a turbulence intensity of $0.88 \mathrm{~m} / \mathrm{sec}$. The growth of the spark-ignited flame kernel was recorded over a time interval from $83 \mu \mathrm{sec}$ to $20 \mathrm{msec}$ following the start of ignition using high speed laser shadowgraphy.

In order to evaluate the effect of ignition spark power, tests were conducted with a long duration ( $\sim 4 \mathrm{msec})$ inductive discharge ignition system with an average spark power of $\sim 14$ watts and two short duration $(\sim 100 \mathrm{nsec})$ breakdown ignition systems with average spark powers of $\sim 6 \times 10^{4}$ and $\sim 6 \times 10^{5}$ watts.

The results showed that increased spark power resulted in an increased growth rate, where the effect of short duration breakdown sparks was found to persist for times of the order of milliseconds. The effectiveness of increased spark power was found to be less at high turbulence and high dilution conditions. Increased spark power had a greater effect on the $0-5 \mathrm{~mm}$ burn time than on the $5-13 \mathrm{~mm}$ burn time, in part because of the effect of breakdown energy on the initial size of the flame kernel. And finally, when spark power was increased by shortening the spark duration while keeping the effective energy the same there was a significant increase in the misfire rate, however when the spark power was further increased by increasing the breakdown energy the misfire rate dropped to zero.

\section{INTRODUCTION}

The performance requirements of gasoline engines have been increasing year by year, resulting in numerous efforts to improve fuel economy, exhaust emissions and engine drivability. Among these are efforts related to enhanced ignition, since the ignition process not only initiates combustion, but can also influence the entire combustion process. The effect of the ignition system on engine combustion has been studied by numerous investigators, particularly in relationship to lean burn engine strategies. Ignition system parameters can be separated into two categories; those relating to the spark plug and those relating to the electrical energy supply system. Studies related to the spark plug itself include investigations of the effect of electrode material [1], diameter [2,3], and orientation [4]; as well as more drastic changes to the standard J-gap design such as surface gap plugs [5,6] and plasma jet ignitors [7]. Numerous studies have also been made of the effect of the rate and duration over which energy is delivered to the spark, in most cases relative to conventional J-gap plugs. In other words, attempting to determine the optimum spark power, energy and/or duration. These include studies of the effect of long duration sparks [5,8,9], multiple sparks [10] and short duration sparks [5,6,8,11-14]. Of specific interest in the study reported in this paper is the effect of short duration, breakdown sparks. There have been several studies of breakdown or breakdown-enhanced sparks and their effect on engine performance. The results of these studies are summarized below.

In 1984, Ziegler et al. [14] reported on a comparison between an experimental breakdown ignition system and a conventional transıstorized coil ignition system in a production four-cylinder engine. The delivered spark energy and the electrode spacing were the same for both ignition systems. The duration of the breakdown ignition spark was $\sim 10 \mathrm{nsec}$ with average spark power of $\sim 4$ megawatts, while the duration of the inductive ignition spark was $\sim 2$ msec with an average power of $\sim 20$ watts. In tests conducted at idle and part-load conditions, the breakdown ignition system was found to result in a reduction in the 0 to 5 percent burn time and to extend the lean misfire limit, most significantly at idle. The breakdown ignition system, therefore, allowed for a wider range when setting spark-advance and air-to-fuel ratio, which in turn resulted in improved fuel economy and reduced emissions.

In 1985, Anderson and Asik [5] compared a blast wave ignition system to a conventional and a long duration inductive ignition system using a standard J-gap plug in a fast burn, single cylinder engine operated at $1500 \mathrm{rpm}$. The inductive ignition system had a spark duration of $1.5-2.0 \mathrm{msec}$ (or $4-6 \mathrm{msec}$ for the long duration version) and 
an average spark power of $\sim 15$ watts. The blast wave ignition system was a modified inductive ignition system with an enhanced breakdown discharge. The duration of the breakdown discharge was $50 \mathrm{nsec}$, and the breakdown energy was $25 \mathrm{~mJ}$ corresponding to a spark power of $0.5 \times 10^{6}$ watts. The blast wave ignition system was found to significantly reduce the 0 to $10 \%$ burn time, to improve combustion stability, and to extend the MBT lean limit; however, little effect on the ignition limit was observed.

In 1987, Anderson [8] investigated the effect of spark power with a capacitive discharge, a breakdownenhanced capacitive discharge, a conventional inductive, and a long-duration inductive ignition system on a fast burn, single-cylinder engine. The same J-gap plug design was used in all of the tests. The average spark power was $\sim 15$ watts for the inductive ignition spark, $\sim 10^{3}$ watts for the capacitive discharge spark, and $\sim 10^{6}$ watts for the breakdown ignition spark. In comparisons made at idle and light load conditions, the breakdown ignition system produced the fastest burning rate; however, most of its burn time reduction was found to occur in the 10 to $90 \%$ period. This result is in contrast to other results that show the largest reduction in the 0 to $5 \%$ period [14] or in the 0 to $10 \%$ period $[5,6]$. The breakdown ignition system showed only a marginal fuel consumption improvement. The combustion stability with the breakdown ignition system was relatively constant over a range of spark advance or air-to-fuel ratio, but it was worse than with the other ignition systems for low spark advance angles and rich air-tofuel conditions.

In 1988, Pischinger and Heywood [6] compared a conventional inductive ignition system and a breakdown enhanced inductive ignition system with a J-gap plug in a transparent square piston engine. The total supplied spark energy was $60 \mathrm{~mJ}$ for the conventional ignition system and $80 \mathrm{~mJ}$ for the breakdown-enhanced system, where the breakdown energy was $\sim 0.5 \mathrm{~mJ}$ and $\sim 10 \mathrm{~mJ}$, respectively. The tests were conducted at two different in-cylinder flow conditions: a low turbulence (slow-burning) case with a standard intake valve and a high turbulence (fastburning) case with a shrouded intake valve. Faster flame initiation and modest improvements in ignition ability with the breakdown-enhanced ignition system were observed under low turbulence conditions, but were not significant under very lean, high turbulence conditions. This suggested that glow discharge power becomes increasingly important under very lean, high turbulence conditions.

That breakdown ignition systems might affect the engine combustion process differently in different engines is not unreasonable, since spark-ignited flame kernel growth can be significantly affected by the turbulent flow conditions at the spark location. In order to isolate the effects of ignition power and the turbulent flow properties, experiments have been conducted in a turbulent flow system which allows for independent variation of the ignition system parameters and the flow field parameters. The tests were carried out with premixed propane-air at near stoichiometric conditions, with three levels of dilution. To evaluate the effect of ignition spark power, measurements were made of the flame kernel growth using high speed laser shadowgraphy for the case of a long duration glow discharge ignition system and two short duration breakdown ignition systems with different spark energies. The effects of dilution, turbulence, and spark power on the flame kernel growth rate and misfire are presented and discussed.

\section{EXPERIMENT}

TUR.BULENT FLOW SYSTEM - The turbulent flow system used in this research is showri schematically in Figure 1. It consists of three separate gas delivery systems for air, propane, and nitrogen which are used to achieve the desired fuel/air equivalence ratio and dilution level. The gas mixture flows through a one inch diameter pipe with a length-to-diameter ratio of 160 to ensure complete mixing. Immediately upstream of the test section is a sintered bronze plate to prevent flashback. Turbulence is generated by forcing the flow through narrow slots $(0.32 \mathrm{~mm}$ wide by $50.8 \mathrm{~mm}$ long), as illustrated in Figure 1. This produces large vortical structures which then breakup in a converging section before entering the test section, resulting in very high levels of turbulence. The turbulence conditions have been measured with LDV and both the mean velocity and the turbulence intensity have been found to be uniform within $10 \%$ over the test section cross-section. Additional details can be found in reference [15]. The test section is $12.7 \mathrm{~mm}$ by $50.8 \mathrm{~mm}$ in cross-section and $75 \mathrm{~mm}$ long. The wide test section walls are made of quartz to provide optical access for laser shadowgraph measurements. A non-resistive J-gap spark plug with a $1.2 \mathrm{~mm}$ gap is mounted in one of the narrow test section walls. The orientation of the ground electrode plug is perpendicular to the flow to minimize the effect of the wake on the spark channel. 


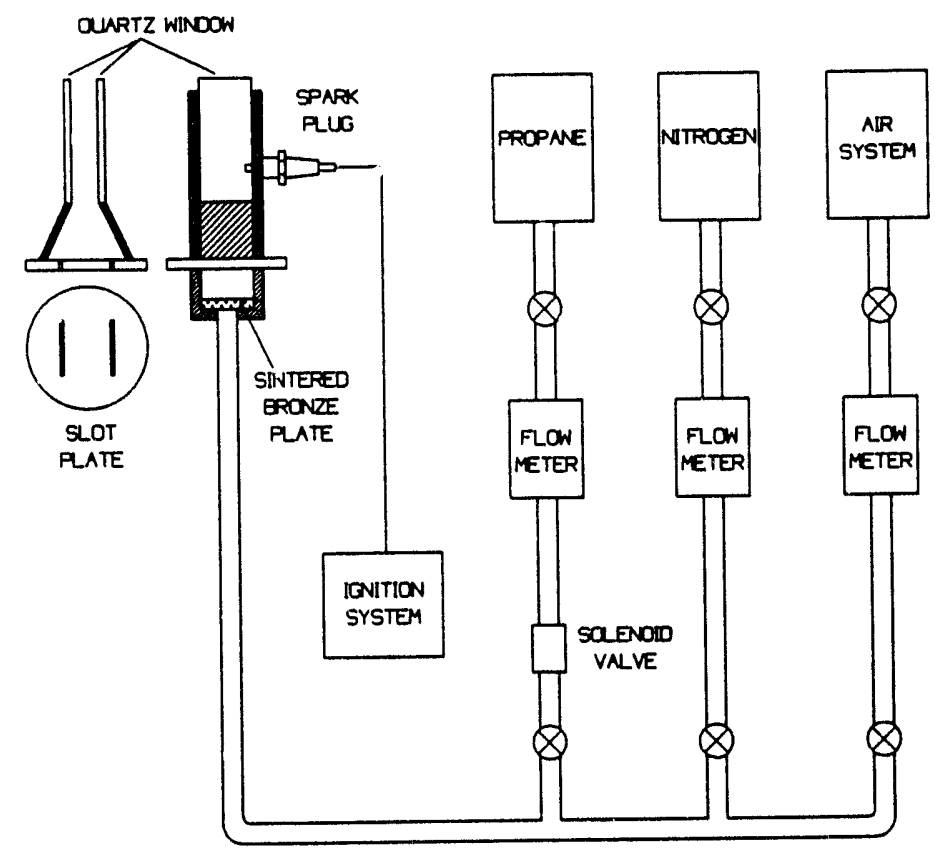

Figure 1. Turbulent flow system.

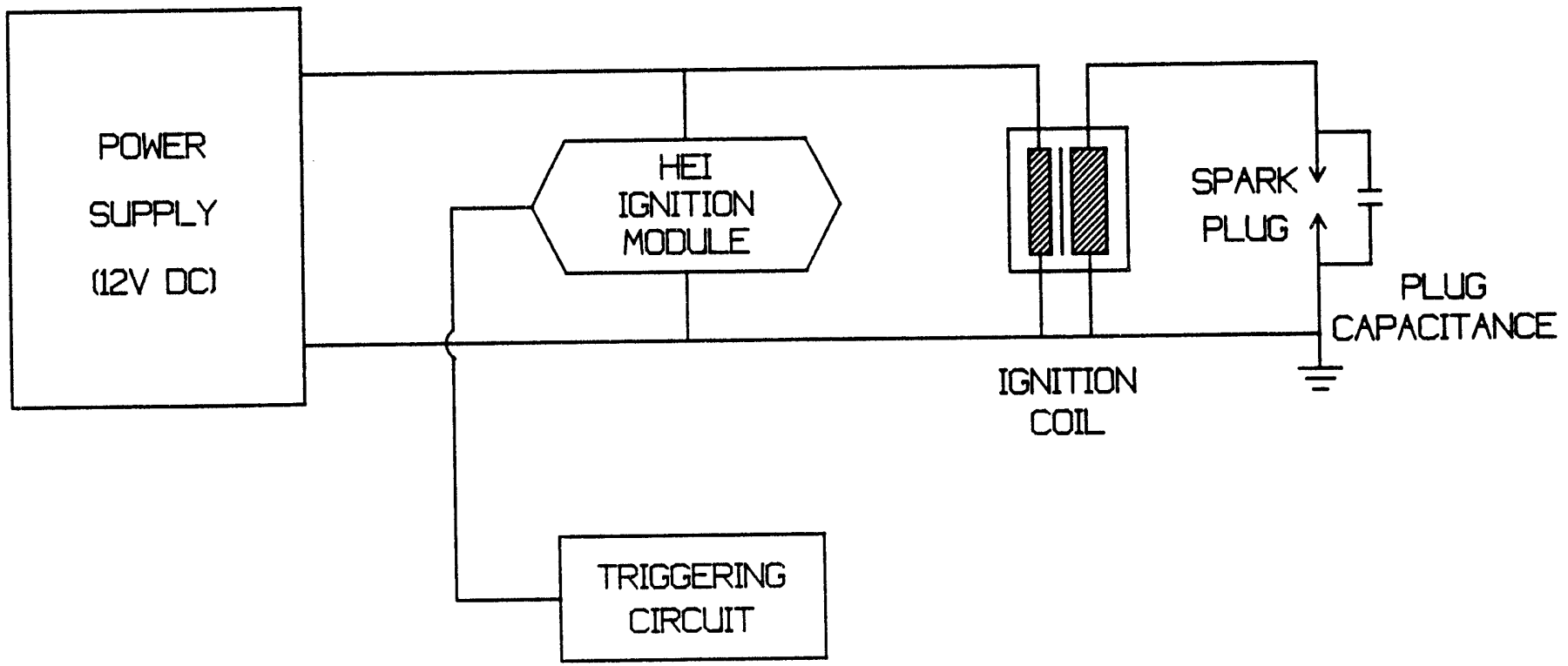

Figure 2. Schematic diagram of the $\mathrm{HEI}$ system. 
IGNITION SYSTEMS - Three ignition systems were used to investigate the effects of ignition spark power on flame kernel growth; a GM High Energy Ignition (HEI) system, a low power breakdown (LPBD) system and a high power breakdown (HPBD) system.

The $\mathrm{HEl}$ system [16] shown in Figure 2, consists of an ignition module, an ignition coil, a triggering circuit, a )-gap spark plug with $1.2 \mathrm{~mm}$ gap spacing (Champion Z-8), and a 12 VDC power supply. The ignition spark is initiated by a $T L$ pulse $(5 \mathrm{~V}$ and $5 \mathrm{msec}$ ) provided by a function generator. Upon receiving the $T T L$ pulse, the ignition module shorts out the primary side of the ignition coil, causing a high voltage rise on the secondary side. The high voltage induced in the secondary coil is routed to the spark plug to produce the ignition spark.

The voltage, current, power and energy characteristics of the spark produced by the HEl system are shown in Figure 3 for the entire ignition period, and in Figure 4 for the initial breakdown phase. The voltage was measured with a high-voltage probe (Tektronics P6015) and the current with an inductive current probe (Pearson Electronics 3464). The voltage and current signals, as well as the power and energy curves, were recorded simultaneously on a digital oscilloscope (HP 54510A). As shown in Figure 3, immediately after the breakdown phase, the voltage drops from a very high level (the breakdown voltage) to a lower level ( $\sim 750 \mathrm{~V}$ ) which is sustained for about 4.2 msec while the current decays gradually from a value of $50 \mathrm{~mA}$. The voltage and current during the breakdown phase, shown in Figure 4, initially rise to peak values of $3600 \mathrm{~V}$ and $5.5 \mathrm{~A}$, respectively, and then drop to lower levels in a very short period of time $(\sim 100 \mathrm{~ns})$. Note that the breakdown voltage is sustained at $3600 \mathrm{~V}$ during the pre-breakdown phase and that the initial voltage rise cannot be seen due to the long pre-breakdown phase of the $\mathrm{HEl}$ spark. Note also that the breakdown voltage and current shown in Figure 3 are not the same as those in Figure 4 , because the oscilloscope cannot resolve the fast breakdown signals in a slow measurement mode. The ignition energy deposited during the breakdown phase was calculated directly from the measured voltage and current, i.e. $E=\int \mathrm{VI} \mathrm{dt}$, and was $0.66 \mathrm{~mJ}$. The lower voltage discharge following breakdown is known as the glow discharge phase $[13,17,18]$ and most of the supplied ignition energy $(\sim 59.1 \mathrm{~mJ})$ is deposited during this phase. The effective energy, defined as the actual energy deposited in the gas mixture, was estimated as $4.73 \mathrm{~mJ}$ for the glow phase and $0.62 \mathrm{~mJ}$ for the breakdown phase $[13,18]$. The HEl ignition system, therefore, operates predominantly in the glow discharge mode. Based on the supplied ignition energy and total duration, the average power for the HEl spark is approximately 14 watts.

The breakdown ignition system (Figure 5) consists of a high-voltage DC power supply, a resistor, a capacitor (470 pF for the LPBD system, or $2500 \mathrm{pF}$ for the HPBD system), a high-voltage vacuum switch (Jennings RGD-1), an external switch, a diode, and a J-gap spark plug with $1.2 \mathrm{~mm}$ gap spacing. The purpose of the diode is to prevent current oscillations when the capacitor discharges into the spark gap. The power supply charges the capacitor to a voltage of $13 \mathrm{KV}$ for both the LPBD and HPBD systems. The ignition spark occurs when the external switch is activated which causes the electromagnetic switch in the vacuum switch to disconnect the power supply from the capacitor and to connect the capacitor and spark plug. Due to losses in the vacuum switch and the diode, only a fraction of the energy stored in the capacitor is transferred to the spark plug. Typical voltage and current signals for the ignition spark produced by the LPBD system are shown in Figure 6 . The voltage and current rise to peak values (3.6 KV and $180 \mathrm{~A}$ ) and decrease very rapidly in a short period ( $100 \mathrm{~ns}$ ). The breakdown voltage for the HPBD system was about the same as that of the LPBD system, but the peak current was much higher ( 800 A).

Table 1 summarizes the characteristics of the three ignition systems. The supplied ignition energy is an average value for 25 ignition events in a propane-air mixture at $300 \mathrm{~K}, 1 \mathrm{~atm}$ and a fuel/air equivalence ratio of 0.93 . The standard deviation of the measured energy, peak voltage, peak current, and peak power was less than $5 \%$. The effective energy is equal to the supplied energy times the energy transfer efficiency which is $8 \%$ for the glow discharge and $94 \%$ for the breakdown discharge $[13,18]$. As shown in Table 1, the estimated effective energies of the $\mathrm{HEI}$ and the LPBD systems are about the same, but the difference in the average spark power is approximately three orders of magnitude. On the other hand, the HPBD system has about the same supplied energy as the HEI system, but its effective energy is about ten times that of the HEI and LPBD sparks and its average spark power is approximately four orders of magnitude greater than that of the HEl spark. 


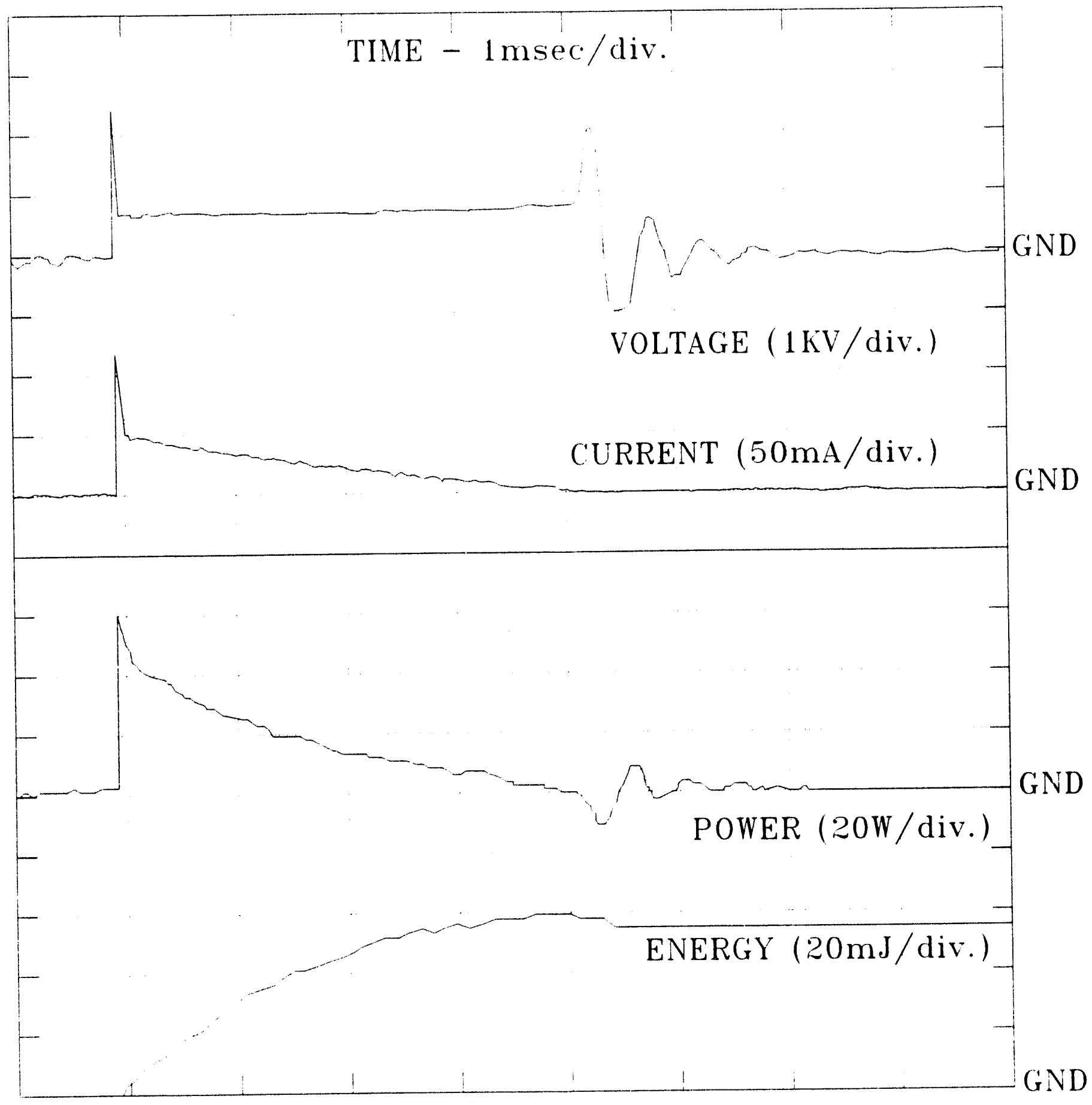

Figure 3. Voltage, current, power and energy versus time (1 $\mathrm{msec}$ per division) for the $\mathrm{HEI}$ spark. 


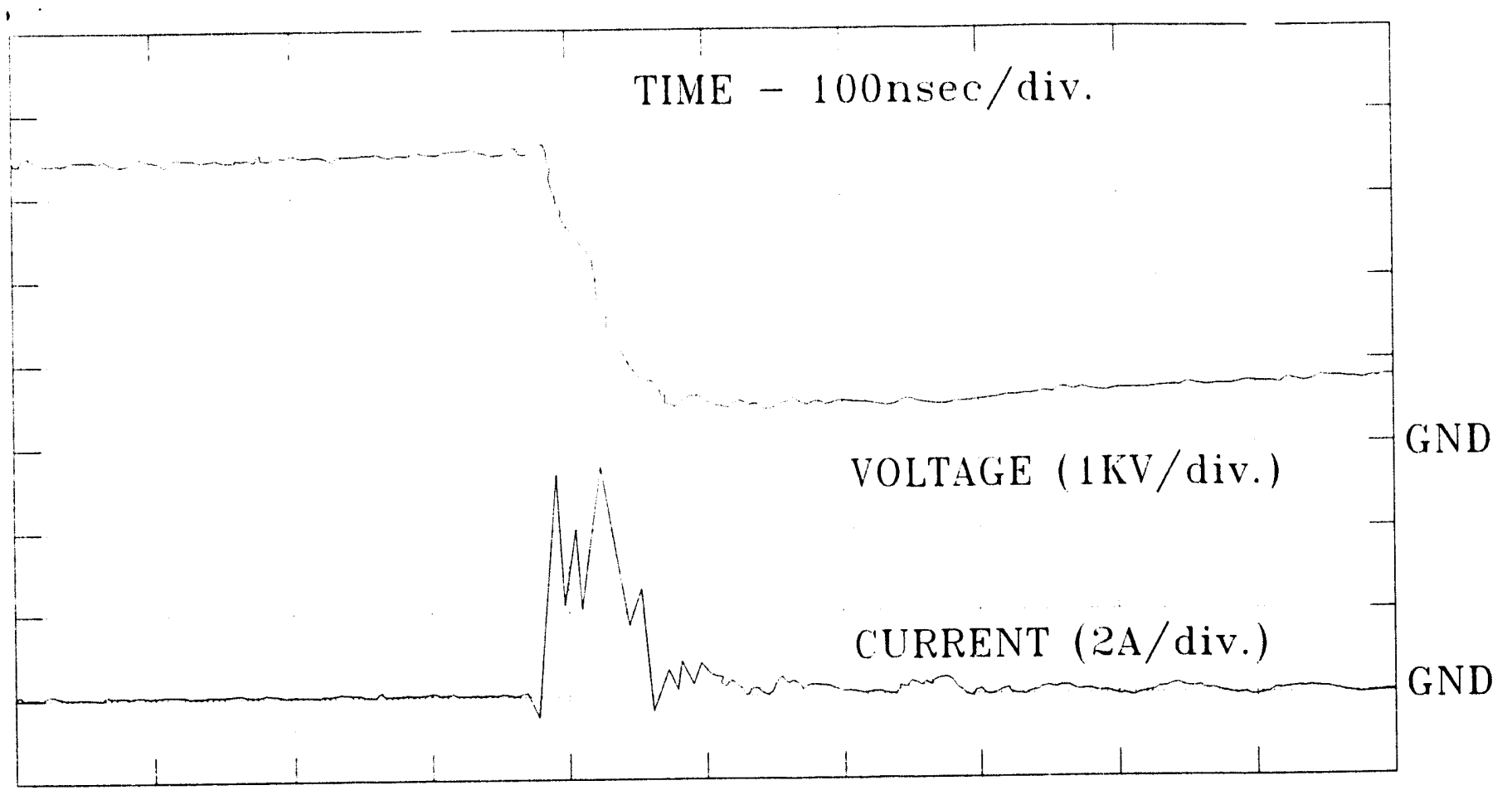

Figure 4. Voltage and current versus time (100 nsec per division) for the HEI spark during the breakdown phase.

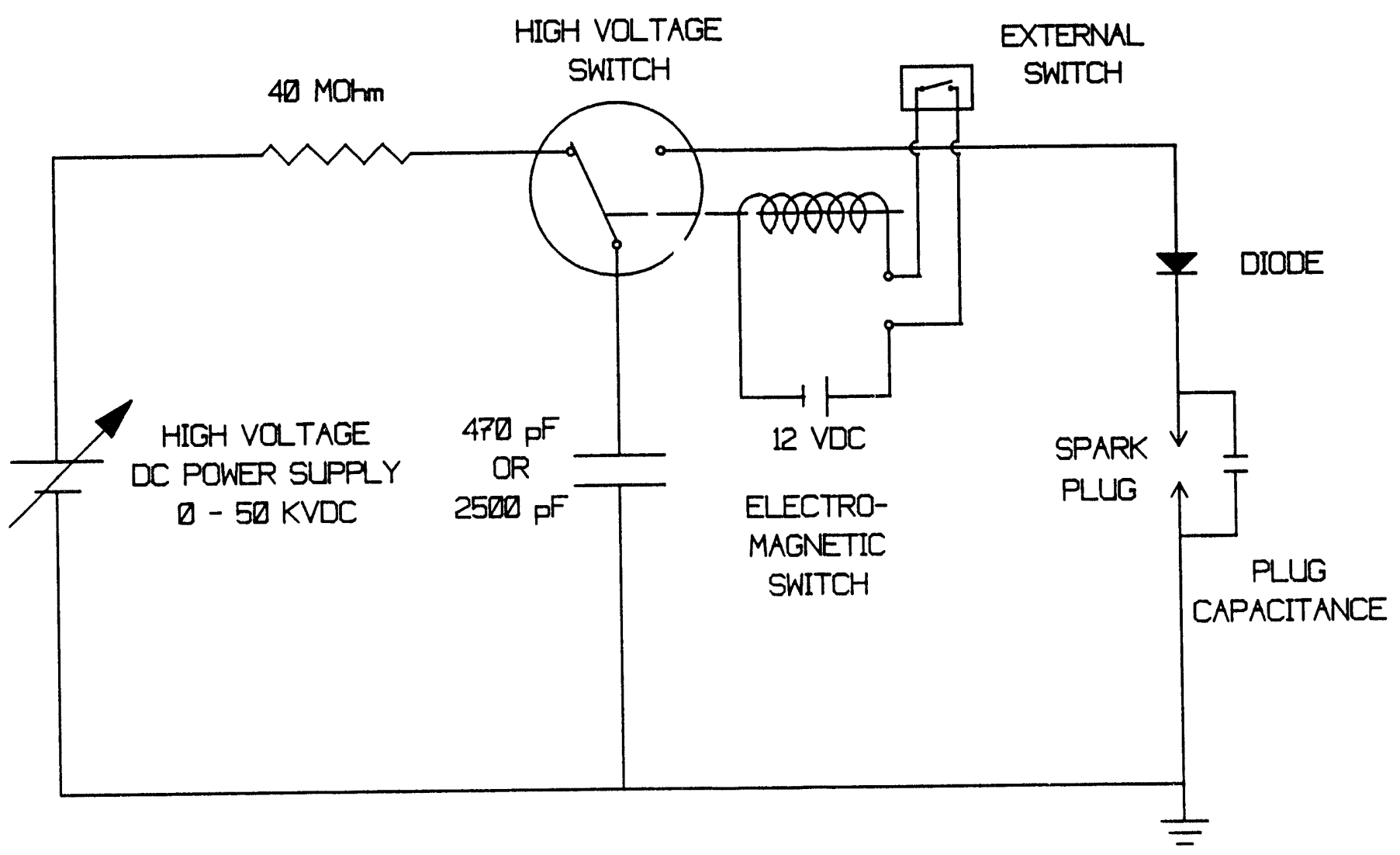

Figure 5. Schematic diagram of the LPBD and HPBD system. 


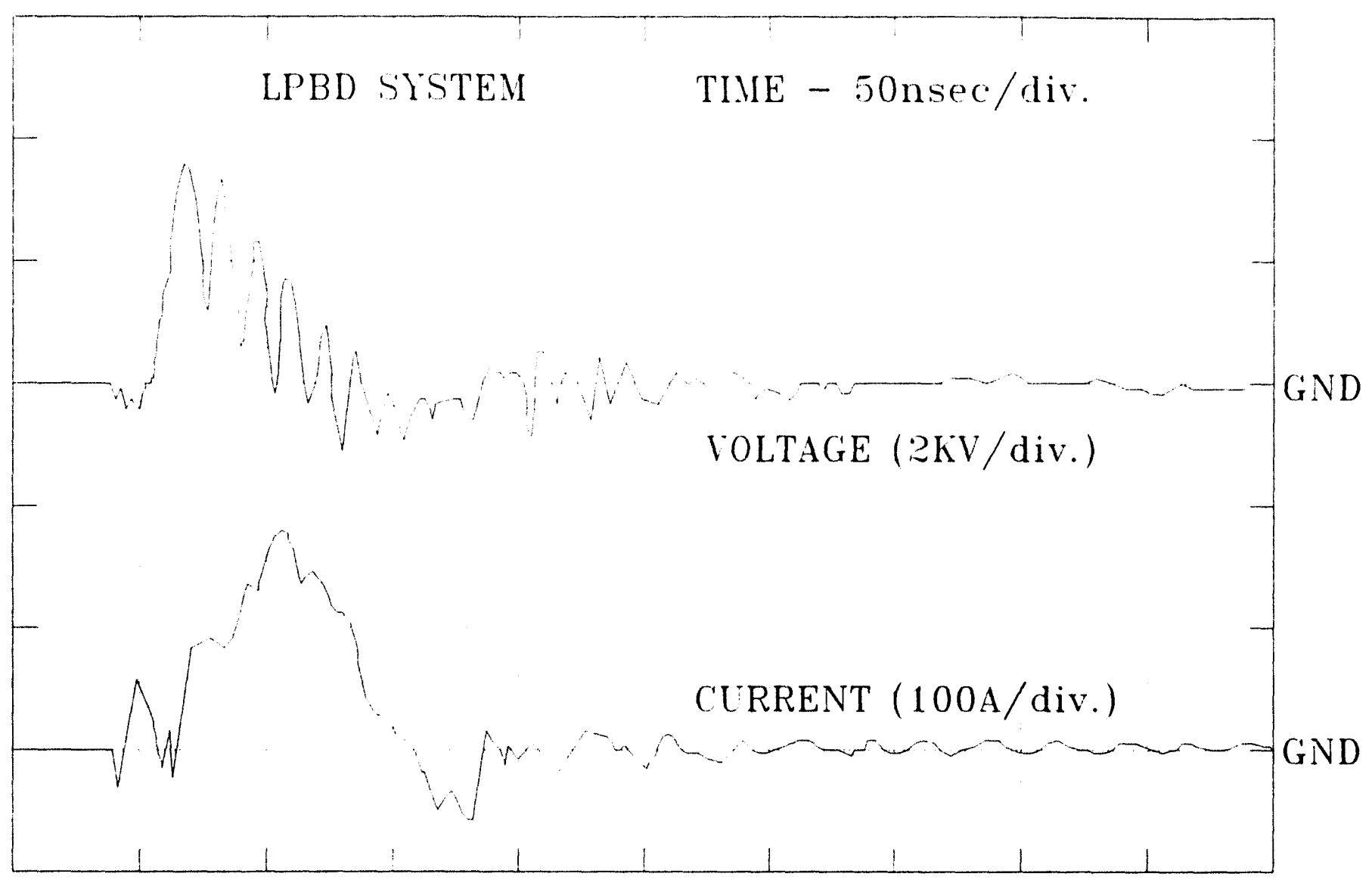

Figure 6. Typical voltage and current versus time ( $50 \mathrm{nsec}$ per division) for the LPBD spark.

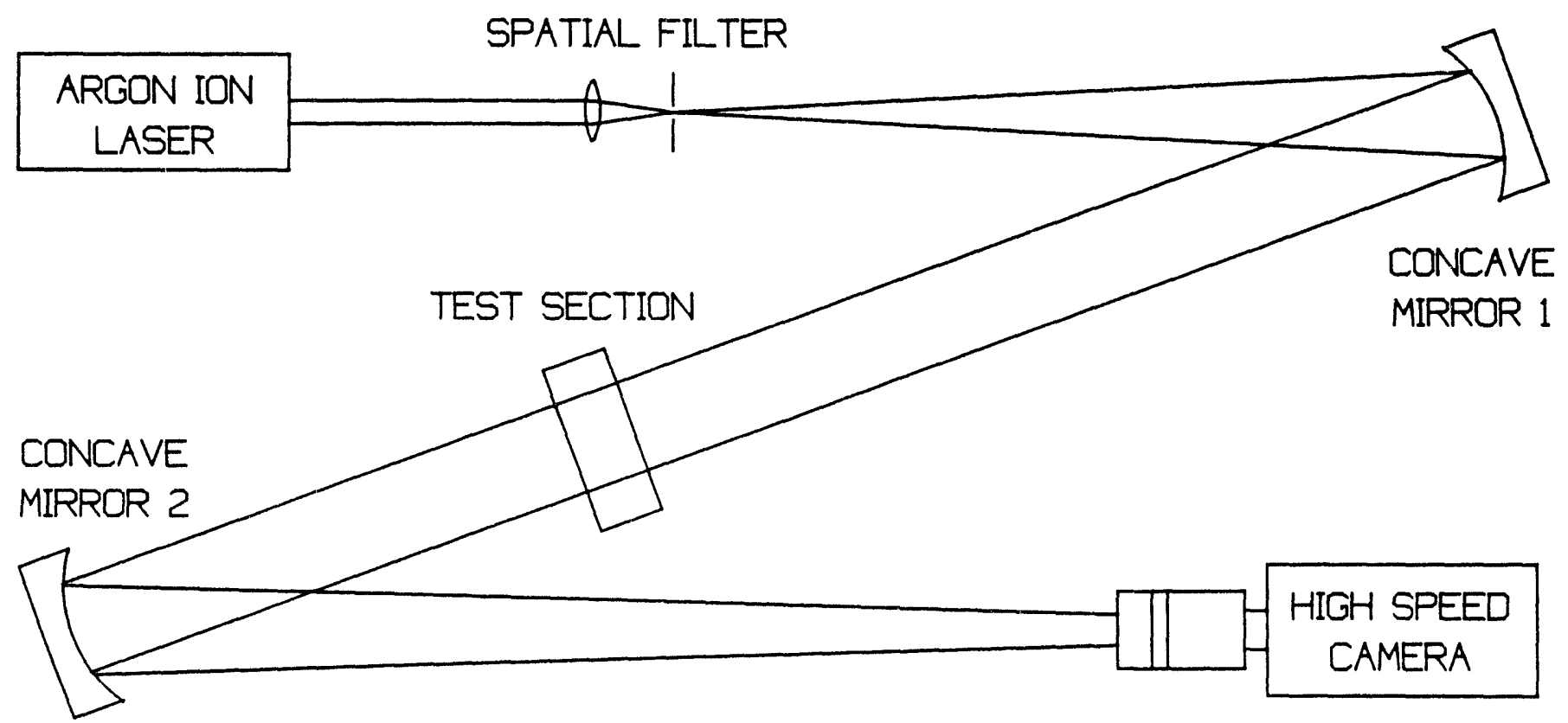

Figure 7. Schematic diagram of laser shadowgraphy technique. 
Table 1. Ignition System Characteristics

\begin{tabular}{|l|ccc|}
\hline Ignition system & HEI & LPBD & HPBD \\
\hline Supplied ignition energy & $59.8 \mathrm{~mJ}$ & $5.7 \mathrm{~mJ}$ & $60 \mathrm{~mJ}$ \\
$\quad$ Breakdown phase & $0.66 \mathrm{~mJ}$ & $5.7 \mathrm{~mJ}$ & $60 \mathrm{~mJ}$ \\
Glow phase & $59.1 \mathrm{~mJ}$ & & \\
Effective ignition energy & $5.35 \mathrm{~mJ}$ & $5.36 \mathrm{~mJ}$ & $56.4 \mathrm{~mJ}$ \\
$\quad$ Breakdown phase & $0.62 \mathrm{~mJ}$ & $5.36 \mathrm{~mJ}$ & $56.4 \mathrm{~mJ}$ \\
Glow phase & $4.73 \mathrm{~mJ}$ & & \\
Spark duration & $-4.2 \mathrm{msec}$ & $\sim 100$ & $\sim 100$ \\
& & nsec & $n s e c$ \\
Avg. supplied spark & $\sim 14 \mathrm{~W}$ & $\sim 57 \mathrm{KW}$ & $\sim 560$ \\
power & & & $\mathrm{KW}$ \\
\hline
\end{tabular}

Table 2. Test Conditions

\begin{tabular}{|l|cc|}
\hline Fuel & \multicolumn{2}{|c|}{ Propane $(\phi=0.93$, premixed) } \\
Diluent & Nitrogen $(0,8$ and $14 \%$; premixed $)$ \\
Pressure & \multicolumn{2}{|c}{$1 \mathrm{~atm}$} \\
Temperature & \multicolumn{2}{|c}{$300 \mathrm{~K}$} \\
Flow Characteristics & Low & High Turbulence \\
Mean velocity & Turbulence & $1.04 \mathrm{~m} / \mathrm{sec}$ \\
Turbulence intensity & $1.25 \mathrm{~m} / \mathrm{sec}$ & $0.88 \mathrm{~m} / \mathrm{sec}$ \\
Relative turbulence & $0.33 \mathrm{~m} / \mathrm{sec}$ & $85 \%$ \\
intensity & $27 \%$ & $\sim 4 \mathrm{~mm}$ \\
Integral length scale & $-4 \mathrm{~mm}$ & \\
\hline
\end{tabular}


LASER SHADOWGRAPHY - High speed laser shadowgraphy was used to record the temporal evolution of the spark-ignited flame kernels. The experimental setup is illustrated in Figure 7. The shadowgraph images were recorded using a high speed video camera system (Kodak Spin-Physics SP2000). Measurements were made at 4000 frames per second (fps) for all three ignition systems, which corresponds to $250 \mu$ s between frames. In the case of the HPBD system measurements were also made at $12000 \mathrm{fps}$ to better resolve the early flame kernel growth. At each operating condition, flame kernel images of ten separate ignition events were recorded.

TEST CONDITIONS - Table 2 shows the test conditions used in this experiment. A propane-air mixture with a fuel/air equivalence ratio of 0.93 was supplied to the test section at a flow rate corresponding to a nominal 1 $\mathrm{m} / \mathrm{sec}$ mean flow velocity in the test section. Nitrogen was used as a diluent to simulate the effect of residual gas under idle operating conditions. Dilution levels of $8 \%$ and $14 \%$ were used, where dilution level is defined as the nitrogen volume flow rate divided by the air volume flow rate. The pressure and temperature were 1 atm and 300 $K$, respectively. Two turbulence conditions were used to study the effects of turbulence on flame kernel growth. The mean velocity and turbulence intensity were measured with laser Doppler velocimetry. Measurements were made at nine locations along the centerline of the test section, normal to theoptical path, and at the same height as the spark electrode.

The measured flow characteristics are shown in Figure 8 for the high and low turbulence conditions. The average mean velocity and turbulence intensity were 1.25 and $0.33 \mathrm{~m} / \mathrm{sec}$, respectively, in the low turbulence case, and 1.04 and $0.88 \mathrm{~m} / \mathrm{sec}$, respectively, in the high turbulence case. Relative to the flow conditions in an engine, these turbulence levels could correspond to a ratio of turbulence intensity to mean piston speed (for a $10 \mathrm{~cm}$ stroke and $800 \mathrm{rpm}$ ) of $\sim 1 / 10$ and $\sim 1 / 3$, respectively. The integral length scale was estimated to be $4 \mathrm{~mm}$, based on iwopoint spatial correlation measurements made in a nearly identical flow system [15].

ANALYSIS METHOD - The flame kernel images recorded on the Spin-Physics system were transferred to 35 $\mathrm{mm}$ slides for the HEI and LPBD measurements by photographing the images on the monitor, and to VHS tape for the HPBD measurements. The slides of the flame kernel images were then projected onto a transparent digitizing table using a slide projector. The images on the VHS tape were projected onto the table using a front-projection TV. The flame kernel boundary was digitized by manually tracing the flame boundary, and the coordinates were stored in a computer. Based on the $X-Y$ coordinates of the flame kernel boundary and a scale factor, the projected area enclosed by the flame kernel boundary was determined. An equivalent flame kernel radius was defined as that of a semi-circle whose area was the same as the projected area of the flame kernel. This digitizing process was repeated for 10 separate ignition events at each operating condition, producing ten individual equivalent radiusversus-time curves. These ten cases were averaged to yield an average equivalent radius and its standard deviation. The average growth rate was obtained by taking a derivative of the average equivalent radius-versus-time curve.

The average growth rate was compared with the laminar growth rate of the flame kernel at each test condition. Based on continuity, the laminar growth rate is defined as

$$
\left[\frac{d r}{d t}\right]_{\text {lam }}=\frac{\rho_{u}}{\rho_{b}} S_{L}
$$

where $\rho_{\mathrm{u}}$ and $\rho_{\mathrm{b}}$ are unburned and burned gas density, respectively, and $\mathrm{S}_{\mathrm{L}}$ is the laminar flame speed. The burned gas density was calculated using the NASA equilibrium code [19]. The unburned gas density was determined from the ideal gas law. The laminar flame speed for propane-air mixtures as a function of the diluent mass fraction was obtained from

$$
S_{L}=(1-3.0 f) S_{L}(0)
$$

where $S_{L}(0)$ is the unstretched, adiabatic laminar flame speed without dilution and $f$ is the diluent mass fraction [2022]. The unstretched, adiabatic laminar flame speed (in $\mathrm{cm} / \mathrm{sec}$ ) for propane-air mixtures without dilution as a function of fuel/air equivalence ratio at a temperature of $298 \mathrm{~K}$ and pressure of $1 \mathrm{~atm}$ is given by

$$
S_{L}(0)=38.31+24.84(\phi-1)-153(\phi-1)^{2}
$$

where $\phi$ denotes the fuel/air equivalence ratio [23]. 

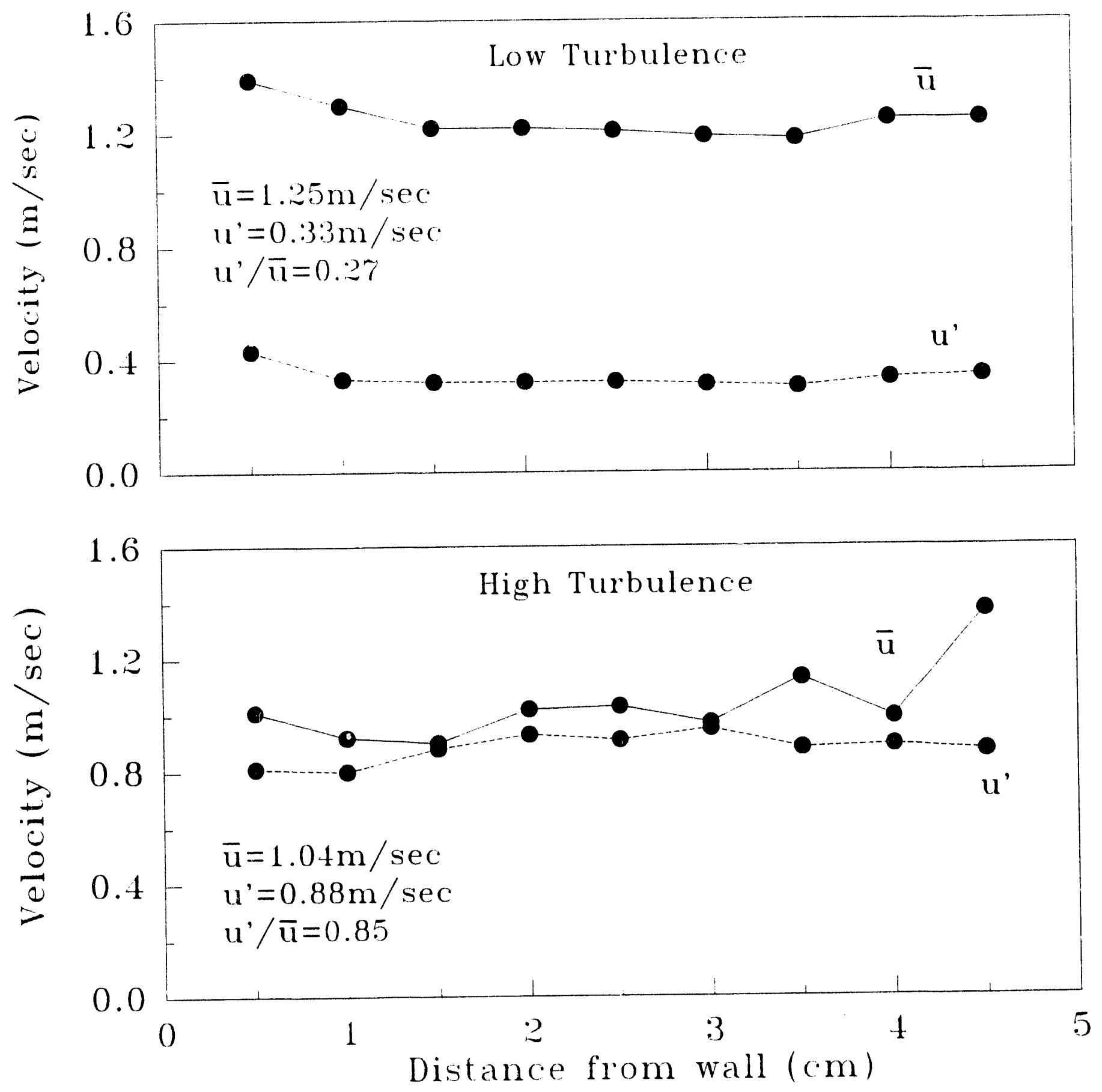

Figure 8. Mean velocity and turbulence intensity profiles for the low and high turbulence cases. 


\section{RESULTS AND DISCUSSION}

Representative sequences of the measured flame kernel boundaries at 1,2,3,4, and 5 msec after the start of ignitic i are shown in Figure 9. These particular results are for the case of $8 \%$ dilution, for both low and high turbulence intensity and for the three ignition systems. As shown, in all cases the flame kernel grows outward from the spark electrode in a somewhat semi-circular shape, but with a noticeable stretching of the flame kernel in the direction of the gas flow. Note, however, that the convection of the flame kernel does not cause it to separate from the electrodes at any of the test conditions. It is also evident that the flame kernel boundary becomes more wrinkled as time progresses due to the turbulent velocity fluctuations, and that both increased turbulence and increased spark power result in more rapid flame kernel growth. A more quantitative analysis of the effects of ignition power, turbulence and dilution on flame kernel growth is given below.

The effect of spark power for the low turbulence, $0 \%$ dilution case is shown in Figure 10, where both the equivalent flame kernel radius and the flame kernel growth rate for the three ignition systems are plotted versus time after the start of ignition. Also shown are the growth rates for the LPBD and HPBD systems normalized by the growth rate for the HEl system.

In order to discuss these and subsequent results, it is useful to divide the flame kernel growth process into three stages. The first stage is what is often referred to as the blast wave phase [24-26] and is the result of the sudden deposition of energy during the breakdown phase of the spark. The blast wave phase lasts less than $10 \mu \mathrm{sec}$ and, therefore, is not resolved in these measurements. The size of the flame kernel after the blast, wave phase, referred to as the initial flame kernel size below, can be estimated from these measurements by extrapolating the radius versus time curve back to $\mathrm{t}=0$.

As shown in Figure 10a, the initial flame kernel size increases with increasing ignition power, or more accurately with increasing breakdown energy. If one assumes that the thermo-chemical state of the flame kernel at the end of the blast wave phase is independent of the breakdown energy, then the initial flame kernel radius should scale with breakdown energy to the one-third power. Although these measurements do not accurately resolve the initial flame kernel radius, it is still clear that the initial flame kernel radius does not increase this rapidly; therefore, the thermo-chemical energy, i.e., the temperature and/or the degree of dissociation and ionization, of the flame kernel must also increase with increasing breakdown energy. This fact will be important in interpreting the growth rate results discussed below.

Following the blast wave phase, the flame kernel begins to grow due to flame propagation and thermal expansion. Factors affecting the rate of flame propagation include fuel type, fuel/air equivalence ratio, dilution, temperature, pressure, flame stretch, preferential diffusion, heat loss, the thermo-chemical state of the gas within the flame kernel, and turbulence. All of these factors, except turbulence, affect flame propagation by directly affecting the laminar flame speed. Of particular relevance to this study is the effect of the thermo-chemical state of the flame kernel, which refers to the temperature and chemical composition of the gas within the flame kernel. As mentioned above, the thermo-chemical energy of the flame kernel at the end of the blast wave phase increases with increasing breakdown energy, although it is not well understood what fraction of that energy goes into thermal energy, i.e., increased gas temperature, as compared to chemical energy, i.e., increased dissociation and ionization. Either case, however, results in increased laminar flame speed [27]. Therefore, the amount of breakdown energy affects both the initial size of the flame kernel and its subsequent growth.

Following the blast wave phase, the flame kernel also grows due to thermal expansion which is simply the volumetric expansion of the flame kernel as a result of heat addition. Factors contributing to thermal expansion are heat loss, chemical heat release and what is referred to as spark assisted growth, which is due to the energy deposited by a long duration spark such as that produced by the HEl ignition system used in this study.

And finally, another important aspect of flame kernel growth during this second stage is the effect of turbulence. To first order turbulence convectively distorts or wrinkles the flame kernel, thereby increasing its surface area and proportionately its burning rate. The full effect of turbulence, however, is not immediately felt by the flame kernel, but increases with time until the size and lifetime of the flarne kernel exceed some multiple of the turbulence 


\section{HEI}
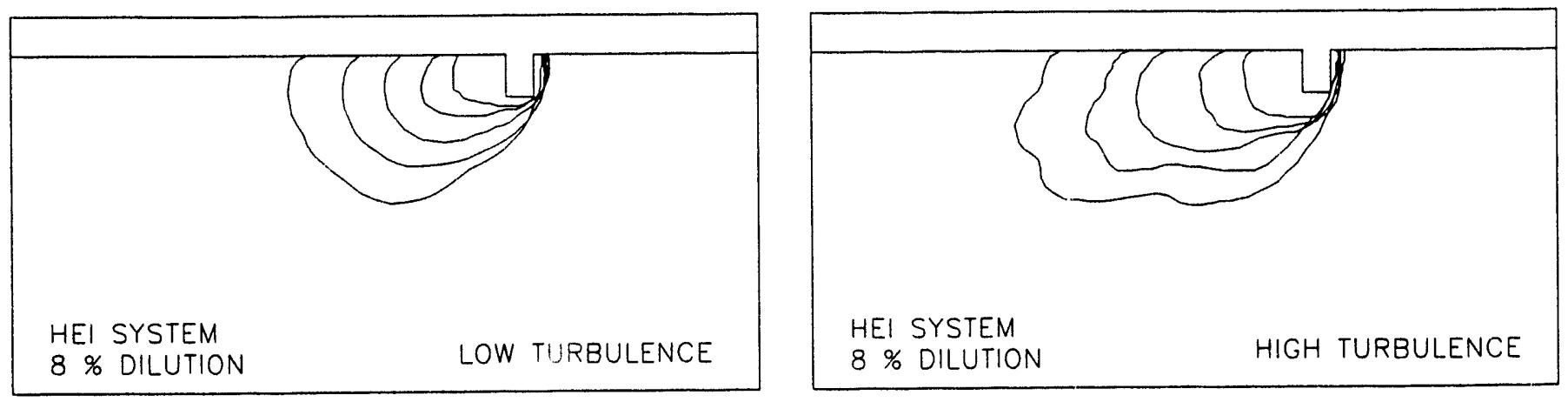

\section{LPBD}
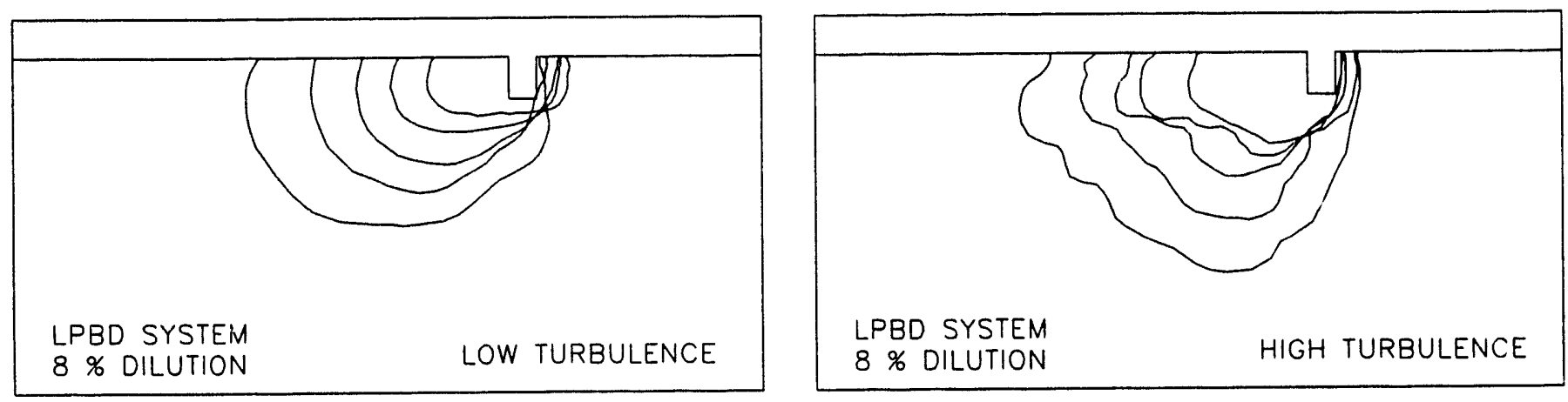

\section{HPBD}
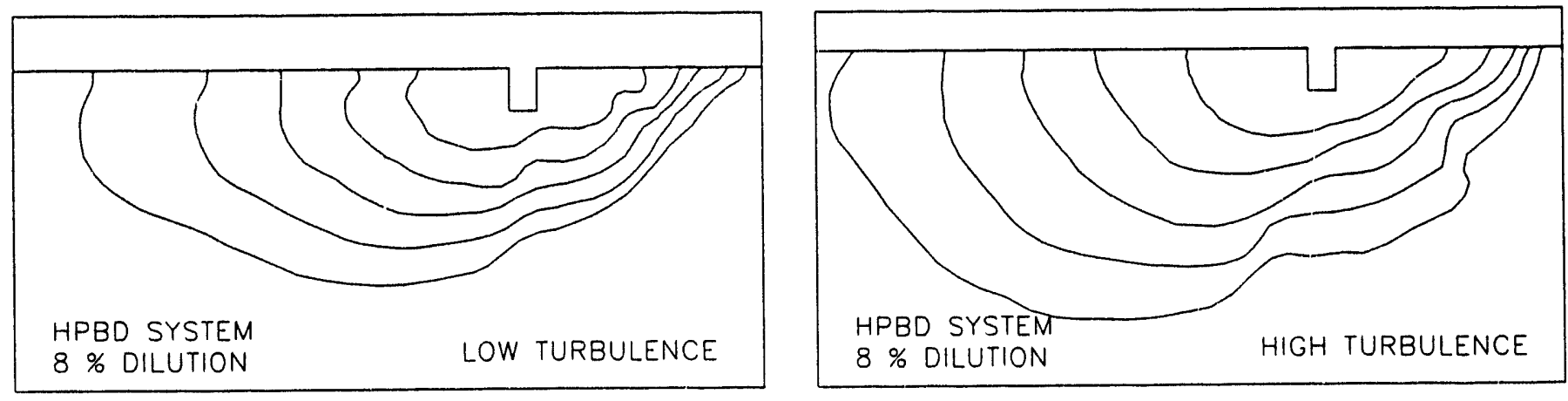

Figure 9. Representative sequences of the measured flame kernel boundaries at 1, 2, 3, 4, and 5 msec after the start of ignition. 


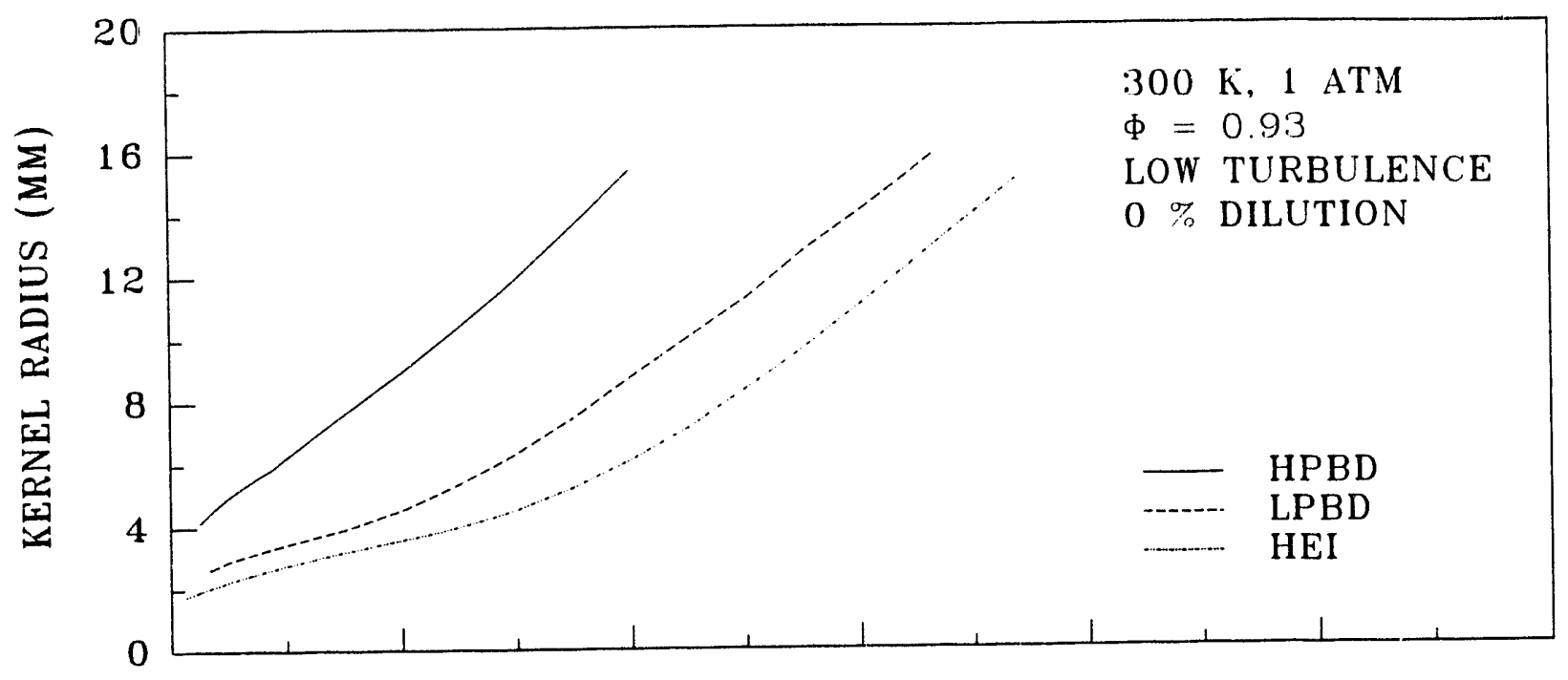

(a)

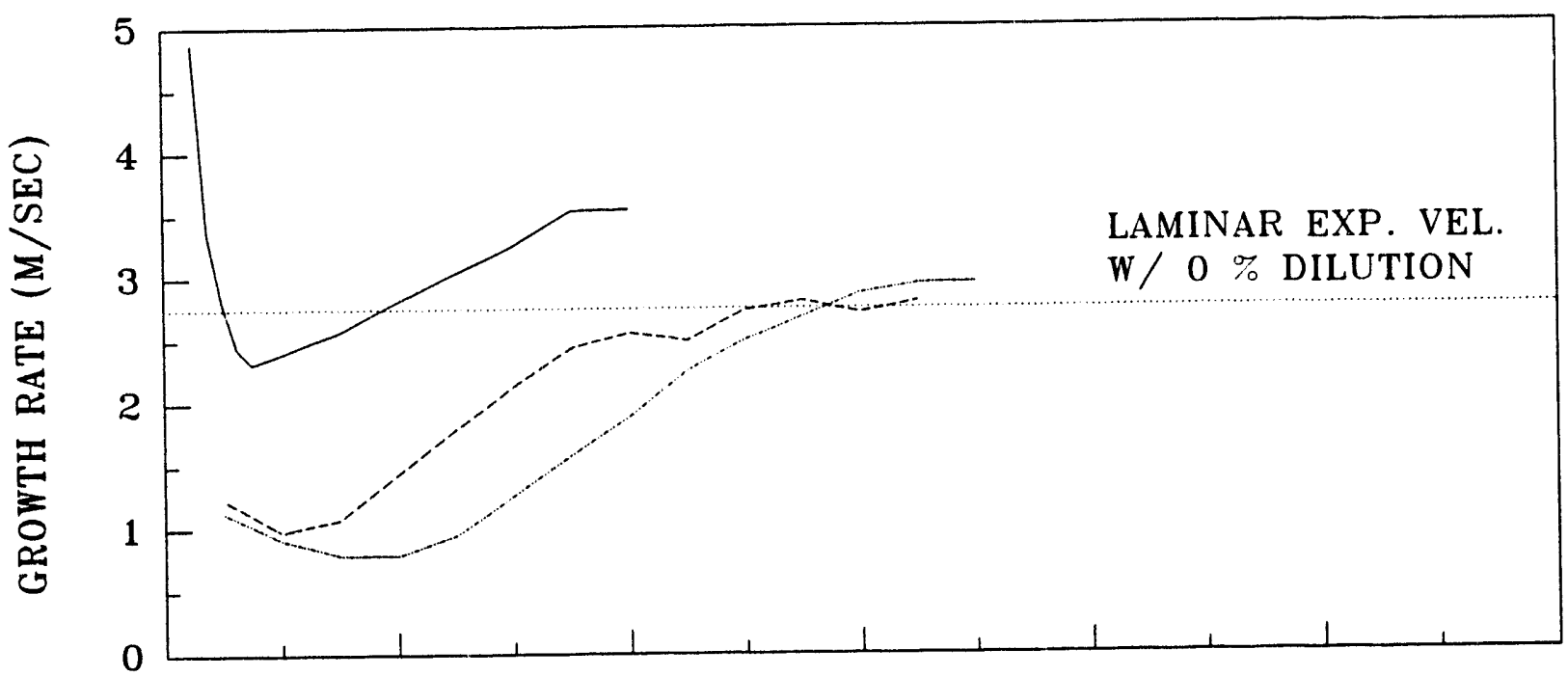

(b)

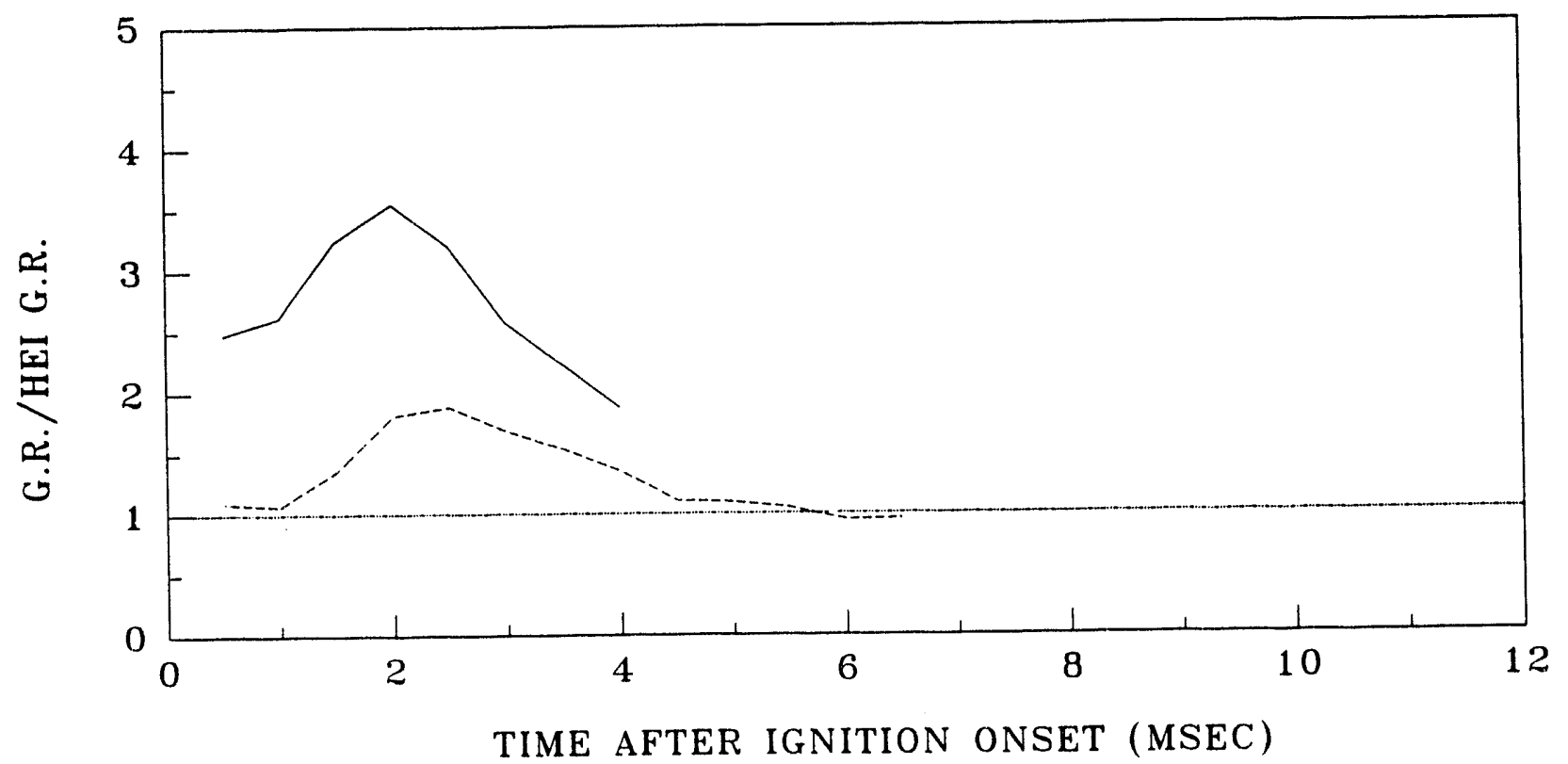

(c)

Figure 10. The effect of ignition spark power on flame kernel growth at low turbulence intensity and with no dilution. 
integral length and time scales, respectively [28]. As a result, due to the effect of turbulence, the flame kernel growth rate increases with time until achieving what is referred to as a fully-developed growth rate. (Note that with sufficiently intense turbulence, turbulent strain may cause a reduction in the burning rate or even extinction of the flame [29].)

With the above considerations in mind, the effect of ignition spark power on the growth rate can be discussed. It is clear from Figure 10a that as the spark power increases, the growth rate increases. The cause of this behavior can be explained more clearly in terms of Figure 10b, where the growth rate is plotted versus time. For comparison, the previously defined laminar growth rate is also shown. The HPBD result shows that the growth rate is initially very large, in fact, many times larger than the laminar growth rate. This can be attributed to the excess thermochemical energy of the flame kernel following gas breakdown, i.e., the greater gas temperature and/or concentration of reactive species, which enhances the laminar flame speed [27]. Unfortunately, the LPBD and HEI measurements were not made at a high enough framing rate to resolve this behavior, although one might reasonably speculate that a similar but smaller effect does occur in these cases. The HPBD result also shows that this initial, large growth rate decreases very rapidly to a value which is less than the laminar growth rate, after which it increases to a value slightly greater than the laminar growth rate. This behavior can be explained in terms of three competing processes. One is the above mentioned effect of the increased thermo-chemical energy of the flame kernel which one would expect to be largest initially and to decrease with time. The second is the combined effect of flame stretch and preferential diffusion, which for a propane-air mixture at a fuel/air equivalence ratio of 0.93 , results in a reduced laminar flame speed, where this effect also decreases in magnitude as the flame kernel radius increases, such that by a radius of 20 to $30 \mathrm{~mm}$ it is nearly negligible [30]. The third effect is due to turbulence, which as discussed above, increases with time as the flame kernel grows until reaching a fully-developed state. In summary, increased thermo-chemical energy and turbulence both act to enhance the growth rate; however, the effect of the former decreases with time, and the latter increases with time, while flame stretch and preferential diffusion act to diminish the growth rate, but less so as the flame kernel gets larger. At long times, therefore, one would expect the flame kernels produced by the three different ignition systems to achieve the same growth rate, i.e., a fully-developed turbulent growth rate.

The HPBD ignition kernel growth rate curve (Figure 10b) can now be explained. The initial, decreasing growth rate can be attributed to the fact that the thermo-chemical effect is decreasing as the thermo-chemical energy diffuses out over a larger flame kernel. During this time, however, one would also expect the effect of flame stretch and preferential diffusion to be important. When the growth rate has fallen to the point where it is equal to the laminar growth rate, i.e., at $-0.5 \mathrm{msec}$, one can argue that the thermo-chemical effect and the flame stretch-preferential diffusion effect must be equal in magnitude (and opposite in sense). Therefore, before that time, the thermochemical effect must be larger, while after that time the flame stretch-preferential diffusion effect must be larger. At $-0.75 \mathrm{msec}$ the growth rate reaches a minimum and begins to increase. This can be attributed to the flame stretch-preferential diffusion effect decreasing more rapidly than the thermo-chemical effect, or to the increasing effect of turbulence, or to both.

The LPBD and HEl growth rate curves in Figure 10b show the same general behavior as the HPBD result, however, the effect of reducing the breakdown energy is also very clear. Because the lower framing rate used for the LPBD and HEI measurements did not resolve to the first $\sim 1 / 2 \mathrm{msec}$ after the start of ignition, the measurements begin slightly before the growth rate curves reach their minimum. At this point, the LPBD and HEI growth rates are nearly the same and approximately a factor of two smaller than the HPBD case. The LPBD curve reaches its minimum somewhat after the HPBD curve and somewhat before the HEl curve, after which they all increase. Again, there are three competing effects which may be causing the growth rate to increase. Comparing the growth rate results for the three ignition systems clearly indicates that increased breakdown energy results in greater growth rates even as long as $4 \mathrm{msec}$ after the deposition of the breakdown energy. There are two possible explanations for this behavis. One is the continued effect of the enhanced thermo-chemical state of the flame kernel and the other is that due to their larger initial size, the higher breakdown energy flame kernels experience the effects of turbulence earlier and therefore grow more quickly. The fact that the LPBD and HEI growth rate curves both appear to be asymptoting to a value nearly equal to the laminar growth rate, whereas the HPBD growth rate is well above the laminar growth rate at these same times, indicates that turbulence is not a significant factor at these conditions and that the effect of the enhanced thermo-chemical state must still be a dominant factor. 
It is particularly interesting to recall that the LPBD and HEl ignition systems provide the same effective energy to the flame kernel; therefore, not only does a higher percentage of the energy supplied by the breakdown mode of the ignition end up in the flame kernel, but that energy has a greater effect on the flame kernel growth rate.

The third and final stage of flame kernel growth is when the flame kernel attains what is refr red to as a fully developed state where the growth rate is constant with time. In this phase, the growth rate is only a function of the properties of the fuel-air-diluent mixture and is no longer affected by the ignition process. As shown in Figure $10 \mathrm{~b}$, the LPBD and HEI results appear to have reached steady state, whereas the HPBD result has not.

Another way to characterize the relative effectiveness of spark power is to plot the HPBD and LPBD growth rates normalized by the HEl growth rate, as shown in Figure 10c. These results show that the effect of increased spark power is actually greatest several milliseconds after the initiation of the spark. This is surprising since at this time, the HEl system is still supplying energy to the flame kernel, whereas the LPBD and HPBD sparks have long since been compleied.

The effect of turbulence on flame kernel growth for the three ignition systems is shown in Figure 11. As expected, turbulence has no effect on the initial flame kernel size. Increased turbulence intensity, though, clearly has an effect on the flame kernel growth rate and, as expected, the effect of turbulence increases with time. The effect of turbulence is most significant for the LPBD case, slightly less for the HEI case, and considerably smaller for the HPBD case. In comparing the LPBD and HPBD growth rates to the HEl growth rate, i.e., Figure 11c, it is apparent that the effect of increased spark power on the growth rate becomes less significant as the effect of turbulence i.e., the turbulence intensity, increases.

The effect of dilution (14\%) on flame kernel growth for the three ignition systems is shown in Figure 12 for the low turbulence condition, and in Figure 13 for the high turbulence condition. Comparing these results to those in Figures 10 and 11, it is apparent that dilution does not have an observable effect on the initial flame kernel size, whereas it is clear that dilution has a significant effect on the growth rate. The general trend of an initially decreasing and then increasing growth rate, which was discussed previously, is observed with dilution as well. For the low turbulence intensity case (Figure 12), the relative effects of increased spark power follow the same general trend with and without dilution-the main difference being that with dilution, the flame kernel takes significantly longer to achieve a given size and a given growth rate. Figure $12 \mathrm{c}$ also indicates that with $14 \%$ dilution the effect of increased breakdown energy on the growth rate actually persists as long as $8 \mathrm{msec}$ after the breakdown process occurs. For the high turbulence intensity case (Figure 13), the HPBD growth rate is approximately a factor of two greater than the $\mathrm{HEl}$ growth rate, while the LPBD and HEI growth rates are nearly the same.

A common method for characterizing the flame kernel growth rate in an engine is in terms of the burn duration, e.g., the $0-10 \%$ burn duration. An analogous concept can be applied to the results from this experiment, as shown in Figure 14, where the $0-5 \mathrm{~mm}$ burn time and the $5-13 \mathrm{~mm}$ burn time are plotted versus percent dilution for the low and high turbulence intensity conditions and for the HEI, LPBD and HPBD ignition systems. This is a concise way of showing the effects of spark power, turbulence and dilution in one figure. In general, both the 0-5 $\mathrm{mm}$ and the 5-13 $\mathrm{mm}$ burn times decrease with increasing spark power, decreased dilution and increased turbulence. The major exception, however, is the 0-5 mm burn time for the HPBD system, which is relatively independent of turbulence and dilution. This is primarily due to the fact that most of the $0-5 \mathrm{~mm}$ growth for the HPBD case occurs as a result of the blast wave process, which is independent of turbulence and dilution. The most significant effect of spark power is observed for the $0-5 \mathrm{~mm}$ burn time between the HPBD case and both the LPBD and HEI cases. This is true at all conditions, however, it become largest with low turbulence and high dilution. There is also a significant effect of spark power observed between the LPBD and HEI systems at low turbulence, high dilution conditions.

And finally, the primary focus of this research is on the effect of ignition spark power on the flame kernel growth rate, where this has direct relevance to the slow-burn limit of an engine's operating range. The ignition process, however, also affects the misfire limit and it is important to distinguish between these two limits and how they relate to the ignition system characteristics. This point is well illustrated by the results shown in Figure 15, where the misfire rate is plotted versus percent dilution for the low and high turbulence conditions and for the three ignition systems. The misfire rate was determined by counting the number of misfire events in 100 igrition attempts. 


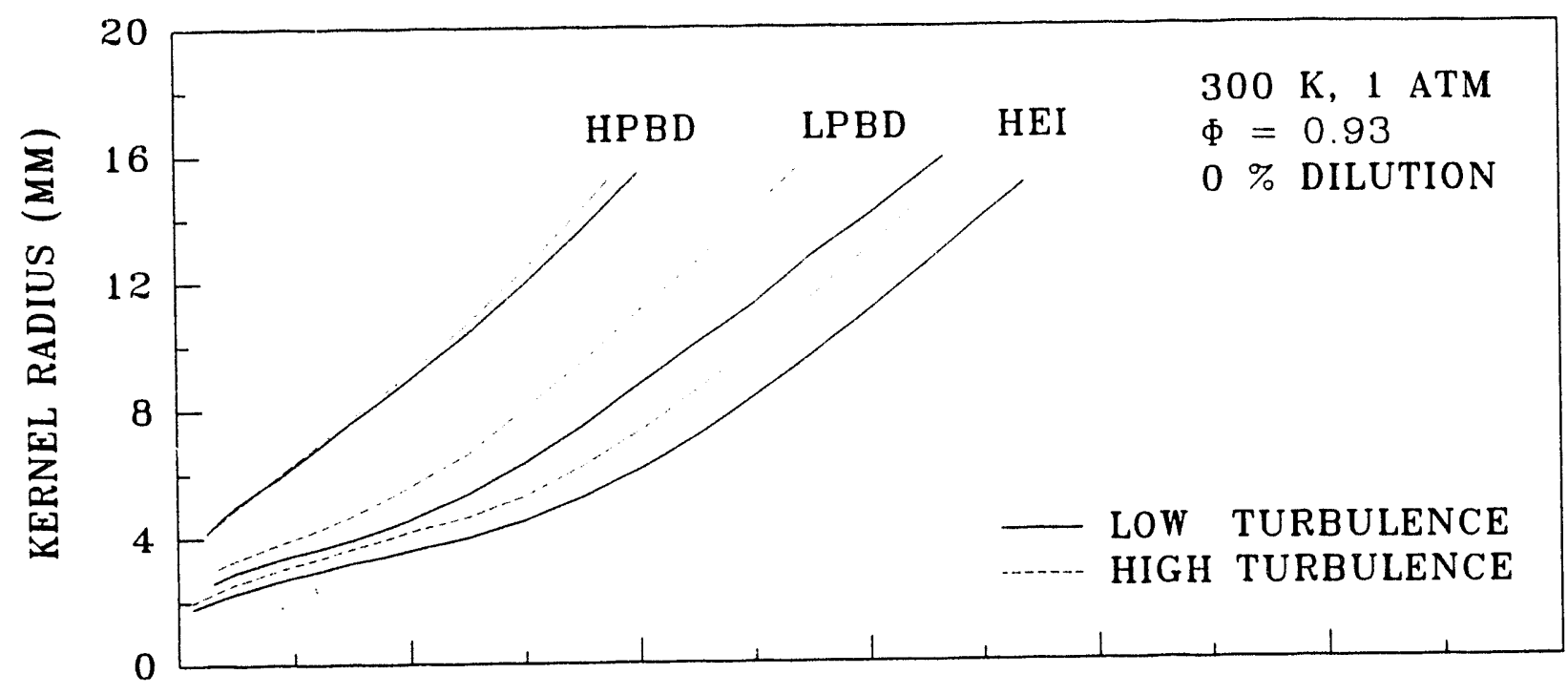

(a)

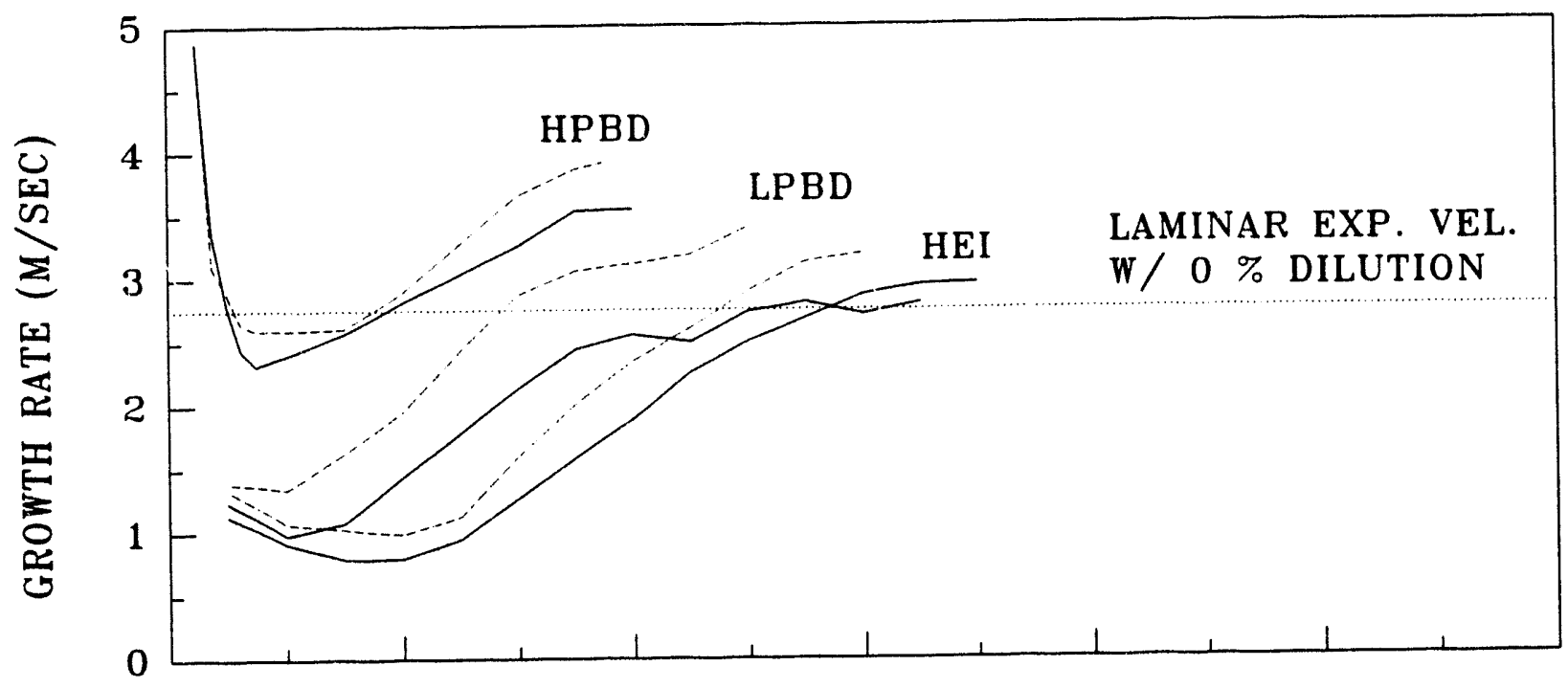

(b)

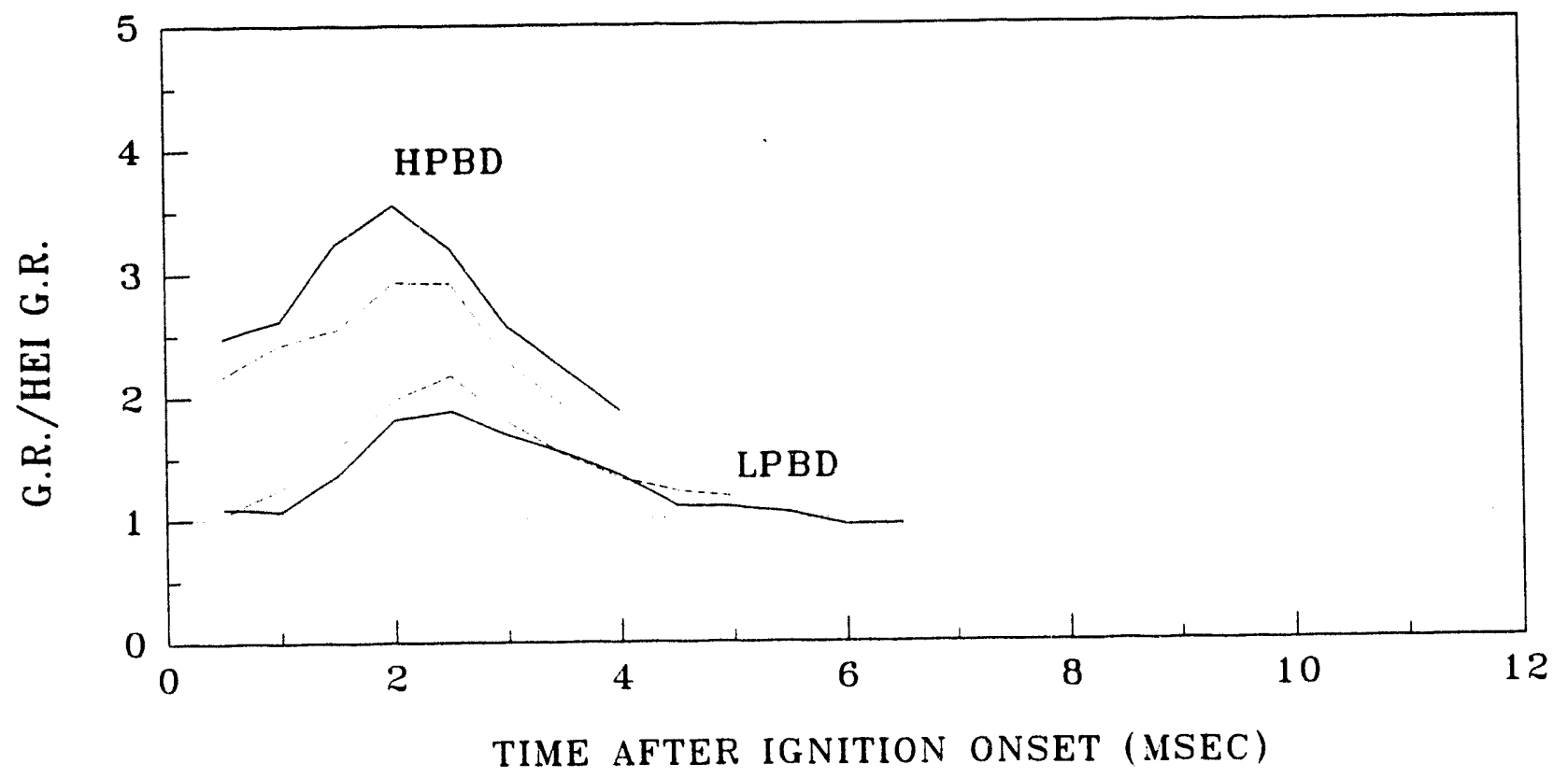

(c)

Figure 11. The effect of ignition spark power on flame kernel growth at low and high turbulence conditions, with no dilution. 


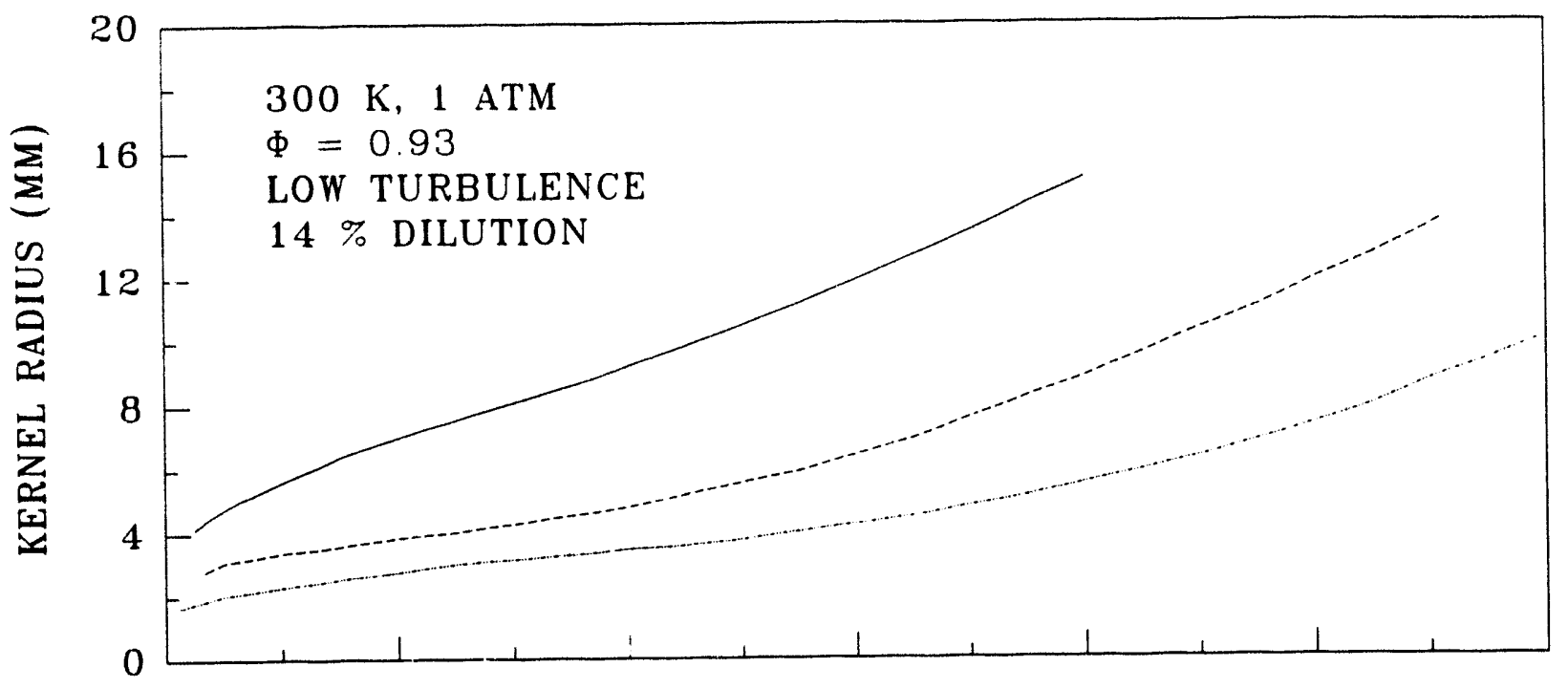

(a)

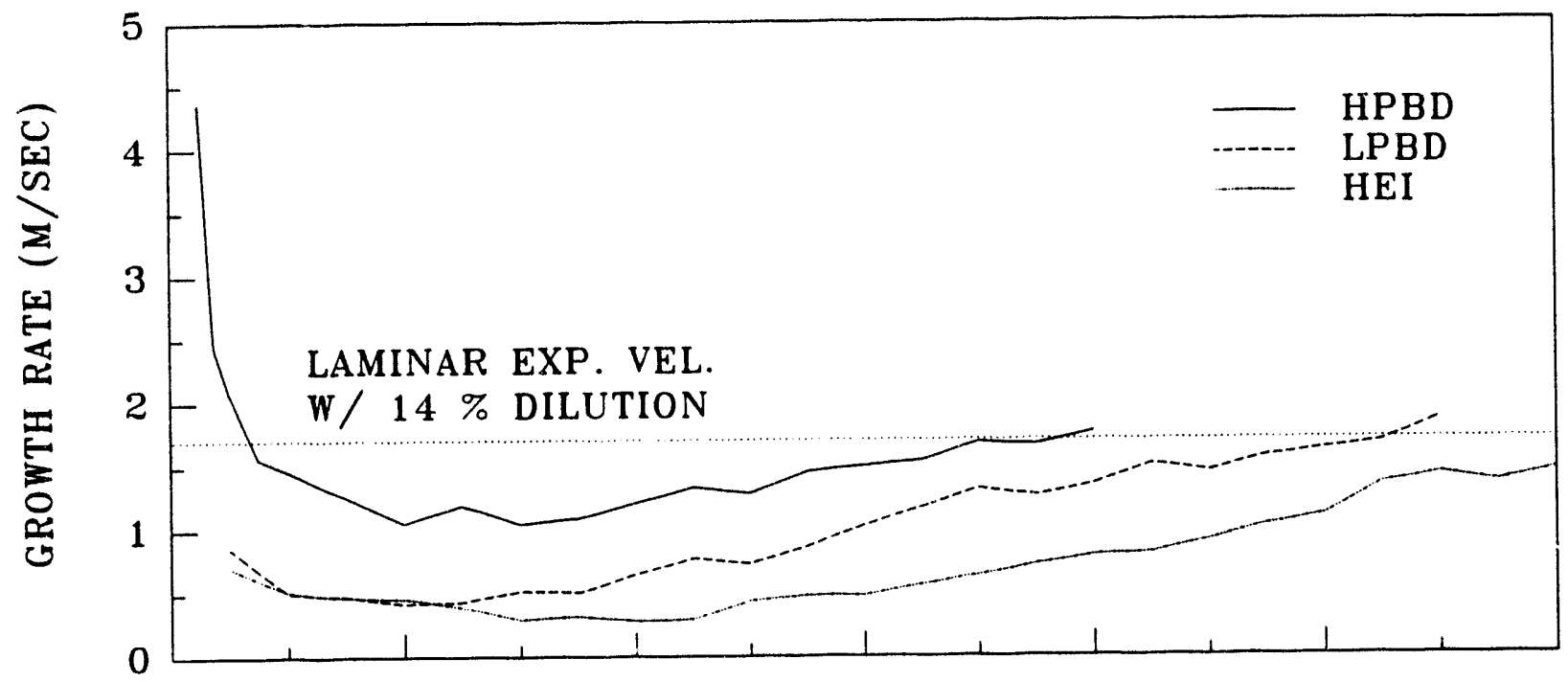

(b)

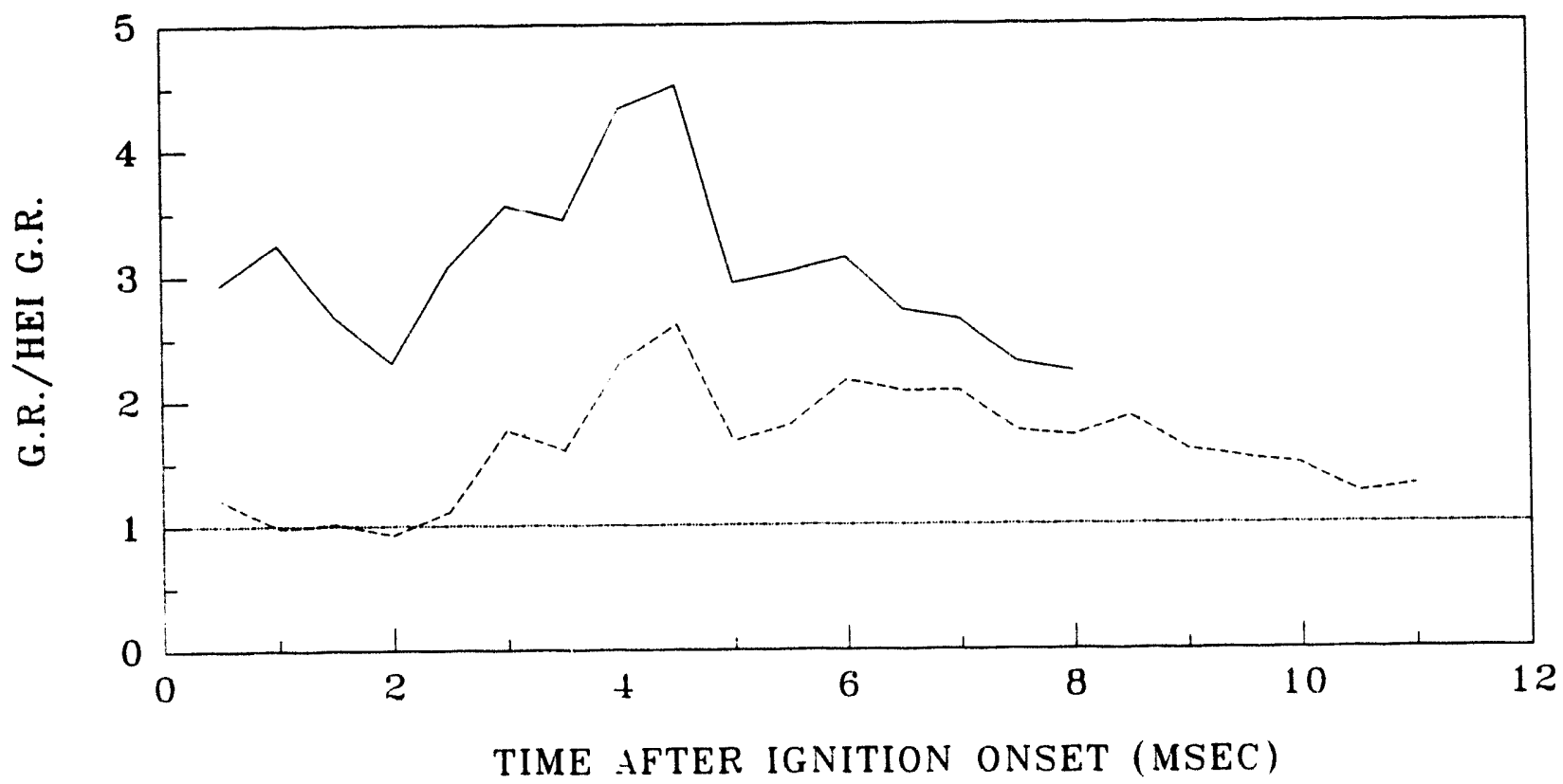

(c)

Figure 12. The effect of ignition spark power on flame kernel growth at low turbulence intensity and with $14 \%$ dilution. 


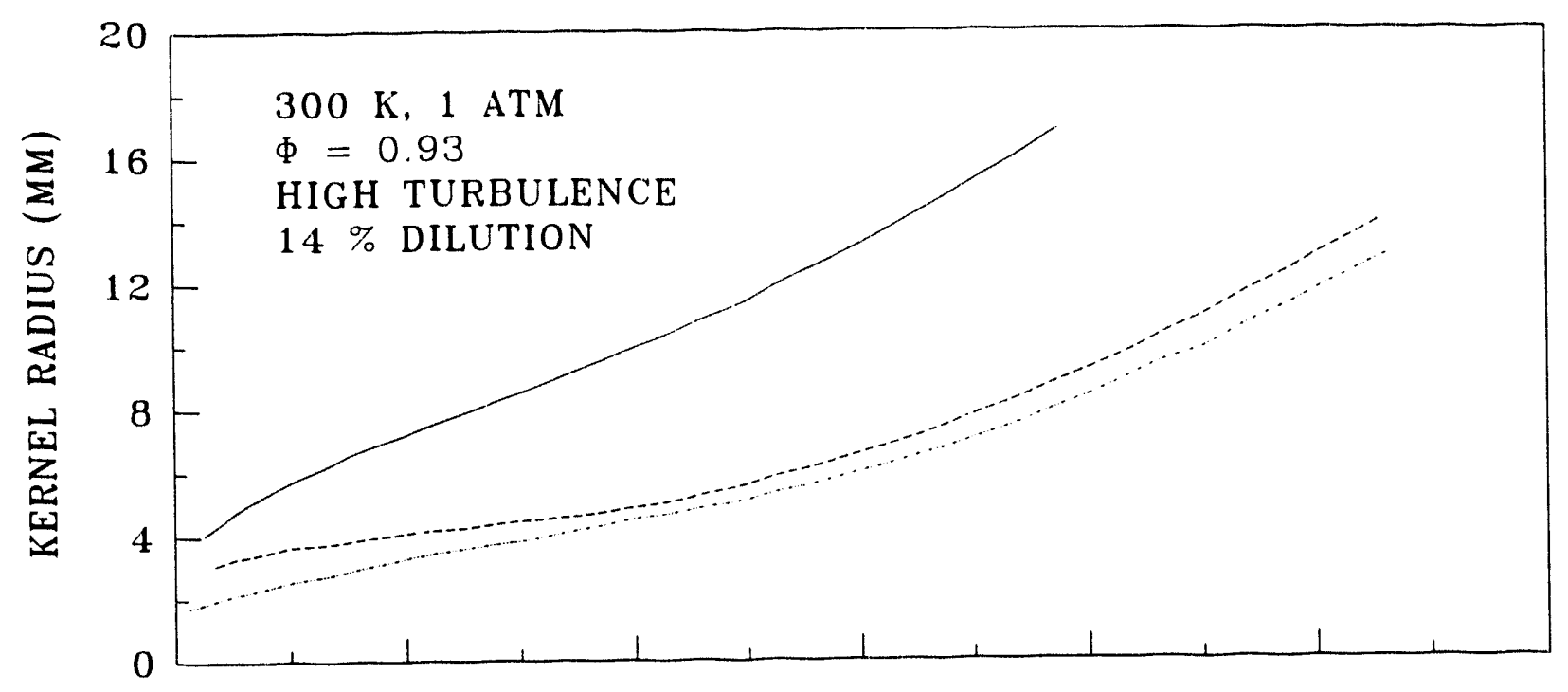

(a)

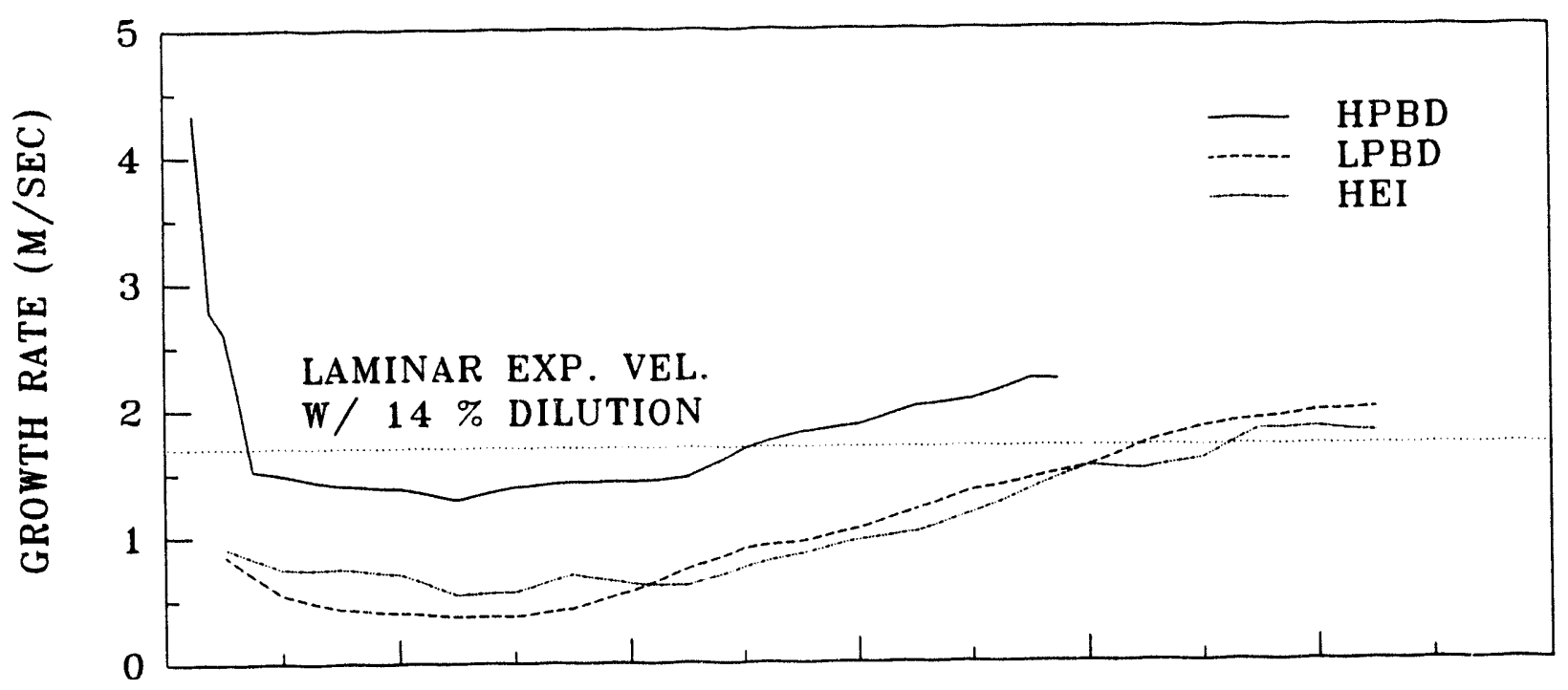

(b)

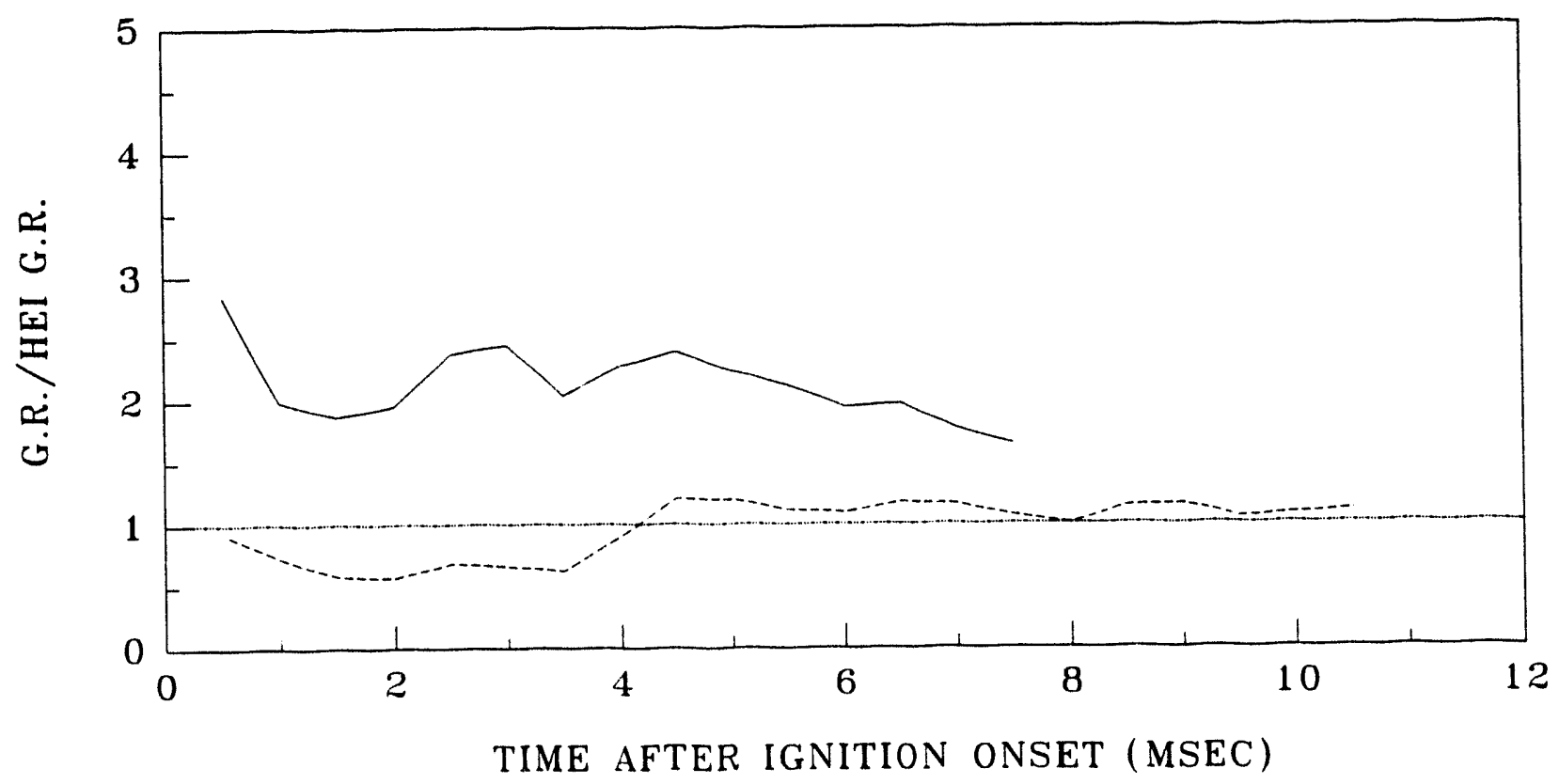

(c)

Figure 13. The effect of ignition spark power on flame kernel growth at high turbulence intensity and with $14 \%$ dilution. 


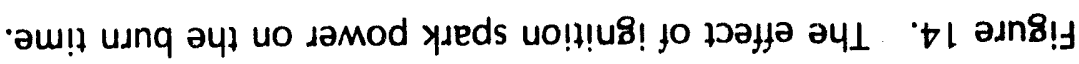

(_ ) NOIJ.LTIO
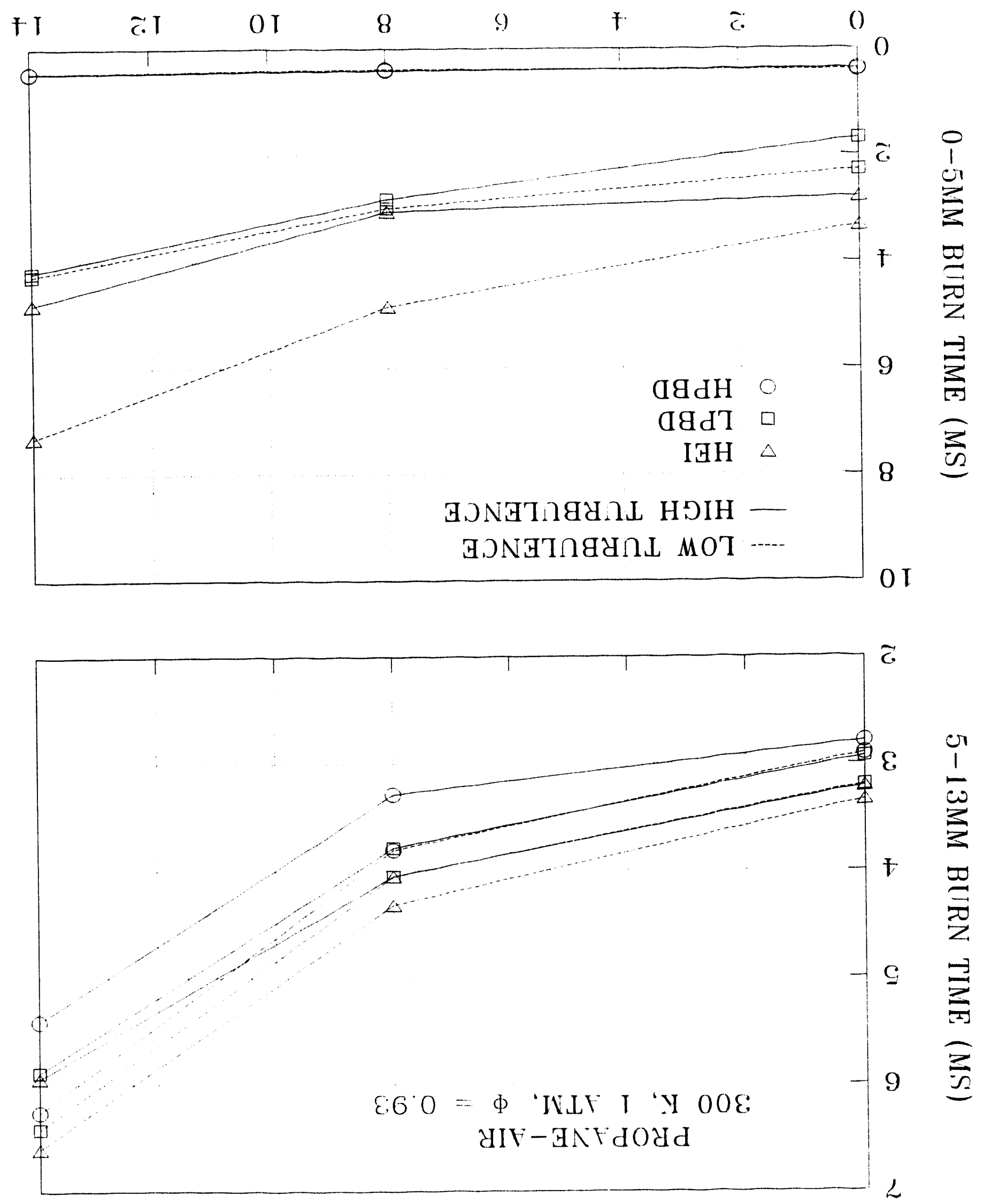


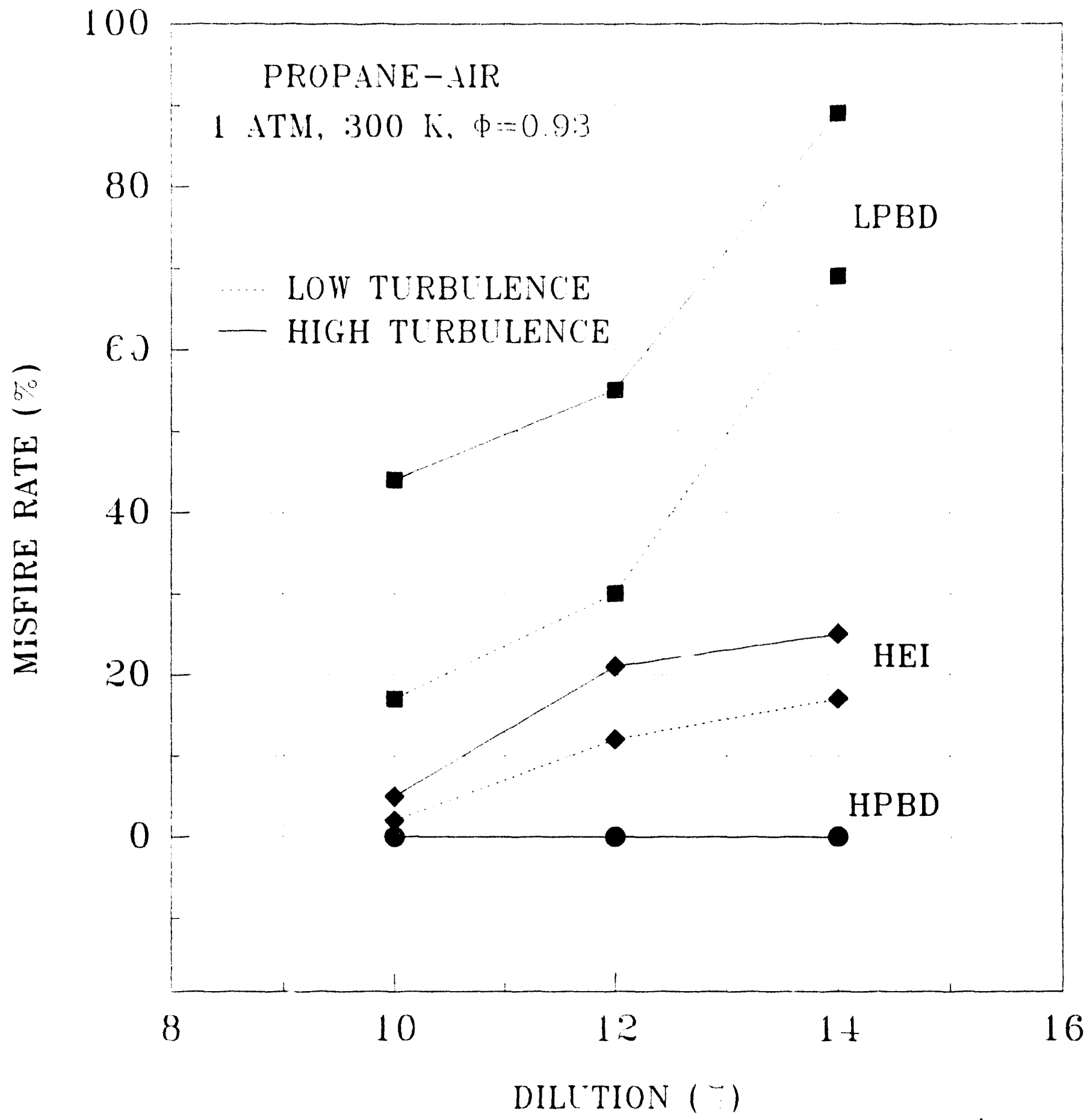

Figure 15. The effect of ignition spark power on the misfire rate. 
Misfire corresponds to a case when the flame kernel grows little if any beyond its initial size after which it extinguishes. This was observed with the high speed shadowgraph system and was found to coincide with the absence of a flame in the turbulence generating section upstream of the test section following ignition; therefore, this simple observation was used to determine whether a misfire occurred. With $8 \%$ dilution all three ignition systems at both turbulence conditions had a zero percent misfire rate; therefore, the misfire measurements were made at 10,12 and $14 \%$ dilution.

The $\mathrm{HEl}$ ignition system misfire rate increased from 2 to $18 \%$ for the low turbulence condition and from 5 to $25 \%$ for the high turbulence condition as dilution was increased. Therefore, both dilution and turbulence increased the misfire rate. The misfire rate for the LPBD ignition system also increased with increasing dilution and turbulence, but it was significantly greater than the $\mathrm{HEl}$ case, e.g., with high turbulence and $14 \%$ dilution, the misfire rate with the LPBD ignition was $90 \%$ compared to $25 \%$ with the HEl system. And lastly, for all conditions tested the misfire rate for the HPBD system was zero. This is significantly different from what was observed in the growth rate results, where increasing ignition spark power in going from the HEI to the LPBD to the HPBD ignition resulted in increasing growth rate at all conditions (except between the HEI and LPBD systems at the $14 \%$ dilution, high turbulence condition when it did not change).

\section{CONCLUSIONS}

The effect of spark power on spark-ignited flame kernel growth was studied in terms of its effect on both the flame kernel growth rate and the occurrence of misfire. The specific manner in which the effect of spark power was studied was to compare a long duration, glow discharge spark to short duration, breakdown sparks. In one case (HEI and LPBD), the effective energy delivered to the flame kernel was the same $(\sim 5 \mathrm{~mJ})$, but there was a factor of $\sim 10^{3}$ difference in spark power. In the other case (HEl and HPBD), the energy supplied by the ignition system was the same $(-60 \mathrm{~mJ})$, but there was a factor of $\sim 10$ difference in the effective spark energy and a factor of $\sim 10^{4}$ difference in spark power. The main conclusions from this study are summarized below:

1. The initial size and thermo-chemical energy of the flame kernel increase with increasing breakdown energy.

2. The increased thermo-chemical energy of the flame kernel caused by increased breakdown energy appears to enhance the flame kernel growth rate well beyond the duration of the breakdown spark, i.e., for times of the order of milliseconds.

3. Not only does the breakdown mode of ignition result in a higher percentage of the energy supplied by the ignition system actually being delivered to the flame kernel, but that energy has a greater effect on the flame kernel growth rate. In other words, a short duration breakdown spark produces a faster growing flame kernel than a long duration spark of equivalent effective energy.

4. Neither turbulence nor dilution affect the initial flame kernel size, i.e., the size following the blast wave phase.

5. For the conditions tested, increased turbulence intensity increased the flame kernel growth rate; however, this effect became less significant as the spark power, i.e., breakdown energy, is increased. As a consequence, the effect of increased spark power on the growth rate is less significant as the turbulence intensity is increased.

6. For the conditions tested, increased dilution reduced the flame kernel growth rate. The effect of increased spark power, i.e., breakdown energy, on the growth rate with and without dilution was relatively unchanged at the low turbulence condition; however, it was significantly reduced at the high turbulence condition.

7. Increased spark power had a significantly larger effect on the $0-5 \mathrm{~mm}$ b1 $\cdots-$ time than the 5-13 $\mathrm{mm}$ burn time. This was particularly true for the HPBD system and under low turbulenc ah dilution conditions.

8. The misfire rate increased with increasing turbulence and dilution for the HEI and LPBD systems. When the spark power was increased by changing from a long duration glow discharge $(H E I)$ to a short duration breakdown discharge (LPBD), with equivalent effective energies, the misfire rate increased. But further 
increasing the spark power of the breakdown discharge (HPBD) resulted in no misfires for all of the conditions tested.

\section{REFERENCES}

1. N. Nakamura, T. Kobayashi, M. Hanaoka and N. Takagi, "A New Platinum Tipped Spark Plug Extends the Lean Misfire Limit," SAE Paper 830479, 1983.

2. S. Pischinger and J. B. Heywood, "How Heat Losses to the Spark Plug Electrodes Affect Flame Kernel Development in an SI-Engine," SAE Paper 900021, 1990.

3. T. Tanuma, et al., "!gnition Combustion, and Exhaust Emissions of Lean Mixtures in Automotive Spark Ignition Engines," SAE Paper 710159, 1971.

4. R. W. Anderson and J. R. Asik, "Ignitability Experiments in a Fast Burn, Lean Burn Engine," SAE Paper 830477, 1983.

5. R. W. Anderson and J. R. Asik, "Lean Air-Fuel Ignition System Comparison in a Fast-Burn Engine," SAE Paper 850076, 1985.

6. S. Pischinger and J. B. Heywood, "A Study of Flame Development and Engine Performance with Breakdown Ignition Systems in a Visualization Engine," SAE Paper 880518, 1988.

7. J. R. Asik, et al., "Design of a Plasma Jet Ignition System for Automotive Application," SAE Paper 770355 , 1977.

8. R. W. Anderson, "The Effect of Ignition System Power on Fast Burn Engine Combustion," SAE Paper 870549, 1987.

9. M. Nakai, Y. Nakagawa, K. Hamai, and M. Sone, "Stabilized Combustion in a Spark-Ignited Engine through a Long Spark Duration," SAE Paper 850075, 1985.

10. J. A. Harrington, R. C. Shinsu, and J. R. Asik, "A Study of Igni, on System Effects on Power, Emissions, Lean Misfire Limit, and EGR Tolerance of a Single-Cylinder Engine - Multiple Spark versus Conventional Single Spark Ignition," SAE Paper 740188, 1974.

11. M. Kono, et al., "Spark Discharge Characteristics and Igniting Ability of Capacitor Discharge Ignition Systems," Combust. Sci. and Tech., Vol. 19, pp. 13-18, 1978.

12. R. Maly, et al., "Prospects of Ignition Enhancement," SAE Paper 830478, 1983.

13. R. Maly, "Spark Ignition: Its Physics and Effect on the Internal Combustion Engine," in: Fuel Economy: Road Vehicles Powered by Spark Ignition Engines, Eds., J. C. Hillard, and G. S. Springer, Chapter III, Plenum Press, 1984.

14. G. F. W. Ziegler, et al., "Influence of a Breakdown Ignition System on Performance and Emission Characteristics," SAE Paper 840992, 1984.

15. B. D. Videto and D. A. Santavicca, "A Turbulent Flow System for Studying Turbulent Combustion Processes," Combust. Sci. and Tech., Vol. 76, pp. 159-164, 1991.

16. G. O. Huntzinger, and G. E. Rigsby, "HEI - A New Ignition System Through New Technology," SAE Paper 750346, 1975.

17. G. F. W. Ziegler, E. P. Wagner, and R. R. Maly, "Ignition of Lean Methane-Air Mixtures by High Pressure Glow and Arc Discharges," 20th Symposium (Int'I) on Combustion, pp. 1817-1824, The Combustion Institute, 1985.

18. R. Maly, and M. Vogel, "Initiation and Propagation of Flame Fronts in Lean $\mathrm{CH}_{4}$-Air Mixtures by the Three Modes of the Ignition Spark," 17th Symposium (Int' $\mid$ ) on Combustion, pp. 821-831, The Combustion Institute, 1978.

19. S. Gordon, and B. J. McBride, "Computer Program for Calculation of Complex Chemical Equilibrium Compositions, Rocket Performance, Incident and Reflected Shocks, and Chapman-Jouguet Detonations," NASA SP-273, 1986.

20. M. Metghalchi, and J. C. Keck, "Burning Velocities of Mixtures of Air with Methanol, Isooctane, and Indolene at High Pressure and Temperature," Combustion and Flame, Vol. 48, pp. 191-210, 1982.

21. T. W. Ryan, III, and S. S. Lestz, "The Laminar Burning Velocity of Isooctane, N-Heptane, Methanol, Methane, and Propane at Elevated Temperature and Pressures in the Presence of a Diluent," SAE Paper 800103, 1980.

22. R. J. Blint, "Flammability Limits for Exhaust Gas Diluted Flames," GM Research Publication, GMR-6036, 1988. 
23. U. Metghalchi, and J. C. Keck, "Laminar Burning Velocity of Propane-Air Mixtures at High Temperature and Pressure," Combustion and Flame, Vol. 38, pp. 143-154, 1980.

24. M. T. Lim, R. W. Anderson, and V. S. Arpaci, "Prediction of Spark Kernel Development in Constant Volume Combustion," Combust. Sci. and Tech., Vol. 69, pp. 303-316, 1987.

25. A. Borghese, et al., "Early Growth of Flames, Ignited by Fast Sparks," Combust. Sci. and Tech., Vol. 76, pp. 219-231, 1991.

26. E. Sher, J. Ben-Ya'ish, and T. Kravchik, "On the Birth of Spark Channels," Combustion and Flame, Vol. 89, pp. 186-194, 1992.

27. T. M. Sloane, "The Effect of Selective Energy Deposition on the Homogeneous Ignition of Methane and its Implication for Flame Initiation and Combustion Enhancement," Combust. Sci. and Tech., Vol. 42, pp. 131-144, 1985.

28. D. A. Santavicca, D. Liou and G. L. North, "A Fractal Model of Turbulent Flame Kernel Growth," SAE Paper 900024, 1990.

29. R. G. Abdel-Gayed, D. Bradley, M. Lawes and F. K-K. Lung, "Premixed Turbulent Burning During the Early Stages of an Explosion," 21st Symposium (Int'l) on Combustion, pp 497-504, The Combustion Institute, 1986.

30. R. A. Strehlow, Combustion Fundamentals, Mcgraw-Hill, p 391, 1984. 

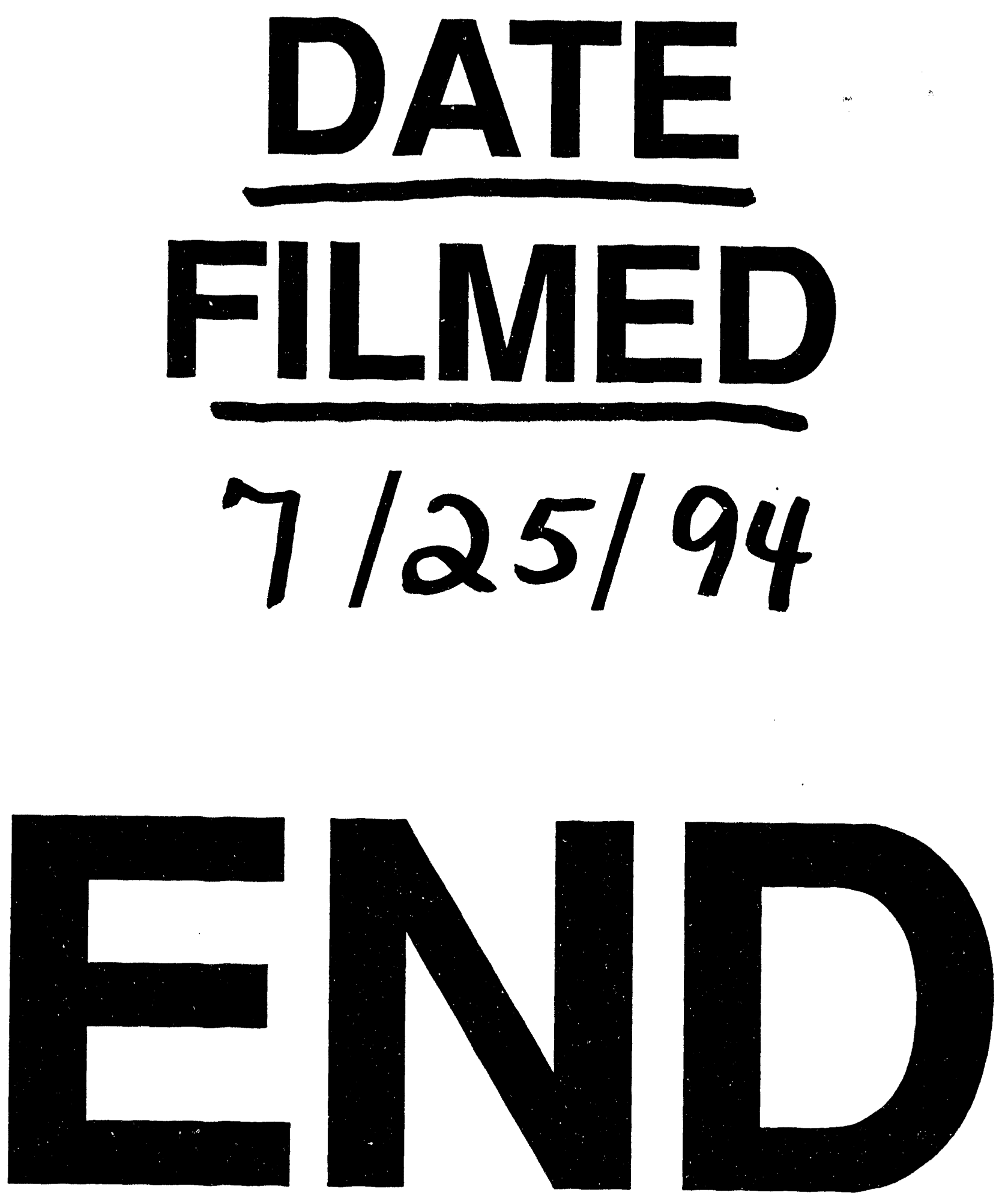